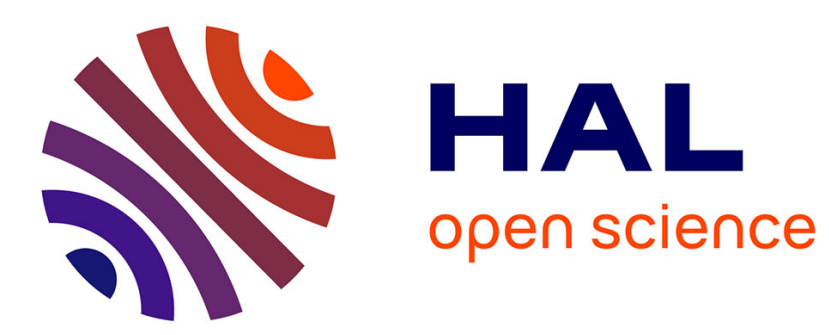

\title{
Muscarinic Modulation of the Trigemino-Reticular Pathway in Lampreys
}

Didier Le Ray, Frédéric Brocard, Réjean Dubuc

\section{To cite this version:}

Didier Le Ray, Frédéric Brocard, Réjean Dubuc. Muscarinic Modulation of the Trigemino-Reticular Pathway in Lampreys. Journal of Neurophysiology, 2004, 92 (2), pp.926-938. 10.1152/jn.01025.2003 . hal-02347069

\section{HAL Id: hal-02347069 \\ https://hal.science/hal-02347069}

Submitted on 7 Nov 2019

HAL is a multi-disciplinary open access archive for the deposit and dissemination of scientific research documents, whether they are published or not. The documents may come from teaching and research institutions in France or abroad, or from public or private research centers.
L'archive ouverte pluridisciplinaire HAL, est destinée au dépôt et à la diffusion de documents scientifiques de niveau recherche, publiés ou non, émanant des établissements d'enseignement et de recherche français ou étrangers, des laboratoires publics ou privés. 


\title{
Muscarinic modulation of the trigemino-reticular pathway in lampreys
}

\author{
by \\ Didier Le Ray ${ }^{2},{ }^{*}$ Frédéric Brocard ${ }^{2},{ }^{*}$ and Réjean Dubuc ${ }^{1,2}$ \\ ${ }^{1}$ Département de kinanthropologie, Université du Québec à Montréal, Montréal (Québec) \\ Canada, H3C $3 P 8$ \\ ${ }^{2}$ Centre de Recherche en Sciences Neurologiques, Université de Montréal, Montréal (Québec), \\ Canada, H3C 3J7
}

Running title: Muscarinic modulation of trigemino-reticular signals

* D.L.R. and F.B contributed equally to this work.

\footnotetext{
$\mathbf{1}^{1}$ To whom correspondence should be addressed:

Dr Réjean Dubuc

Université du Québec à Montréal,

Département de Kinanthropologie,

C.P. 8888 , Succ. Centre-Ville,

Montréal (Québec), Canada H3C 3P8

Tel: (514) 3435729

Fax: (514) 3436611

Email: dubuc.rejean@uqam.ca
} 


\begin{abstract}
In lampreys, reticulospinal neurons integrate sensory inputs to adapt their control onto the spinal locomotor networks. Whether and how sensory inputs to reticulospinal neurons are modulated remains to be determined. We showed recently that cholinergic inputs onto reticulospinal neurons play a key role in the initiation of locomotion elicited by stimulation of the mesencephalic locomotor region in semi intact lampreys. Here, we investigated the possible role of muscarinic acetylcholine receptors in modulating trigeminal inputs to reticulospinal neurons. A local application of muscarinic agonists onto an intracellularly recorded reticulospinal cell depressed the disynaptic responses to trigeminal stimulation. A depression was also observed when agonists were pressure ejected over the brainstem region containing second-order neurons relaying trigeminal inputs to reticulospinal neurons. Conversely, muscarinic antagonists increased the trigeminal-evoked responses, suggesting that a muscarinic depression of sensory inputs to RS neurons is exerted tonically. The muscarinic modulation affected predominantly the NMDA component of the trigeminal-evoked responses. Moreover, atropine perfusion facilitated the occurrence of sustained depolarizations induced by stimulation of the trigeminal nerve and allowed the occurrence of NMDA induced intrinsic oscillations in reticulospinal neurons. The functional significance of a muscarinic modulation of a sensory transmission to reticulospinal neurons is discussed.
\end{abstract}

KEYWORDS: Sensorimotor integration; Reticulospinal neurons; Acetylcholine; NMDA-induced oscillations; CAN current 


\section{INTRODUCTION}

Motor control is based on interactions between centrally generated commands and incoming sensory inputs. These interactions occur at all levels of the CNS from motor networks located in the spinal cord or in the segmental ganglia (in vertebrates and invertebrates, respectively) to the brainstem and forebrain structures (for reviews see Clarac 1991; Rossignol 1996). Although essential, sensory inputs are nevertheless modulated to shape the information in accordance to the state and pattern of activity of the central motor networks as shown in many animal species including invertebrates (Sillar and Skorupski 1986; Le Ray and Cattaert 1999), lower vertebrates such as lampreys (Bussières and Dubuc 1992; El Manira et al. 1997b) and mammals (e.g., cats: Dubuc et al. 1986; Gossard et al. 1989).

In lampreys, reticulospinal (RS) cells constitute the main descending pathway involved in the control of motor behaviors. They activate and control the spinal locomotor networks and integrate sensory inputs from different modalities (Rovainen 1982; Orlovsky et al. 1992; Dubuc et al. 1993a,b; Deliagina et al. 1995; Viana Di Prisco et al. 1995; Zompa and Dubuc 1996), inputs from the spinal locomotor networks themselves (Dubuc and Grillner 1989; Vinay and Grillner 1993; Vinay et al. 1998), and inputs from higher brain centers (El Manira et al. 1997a). One brainstem region projecting to the RS cells is the mesencephalic locomotor region (MLR) recently described in lampreys (Sirota et al. 2000; Brocard and Dubuc 2003; Le Ray et al. 2003). This region is homologous to a region first described in cats and later in several other vertebrate species (for a review see Jordan 1998). We have also shown that the lamprey MLR contains cholinergic cells and provides a nicotinic receptor-mediated excitation of the rhombencephalic RS neurons that contributes to swimming activity (Le Ray et al. 2003). 
The presence of cholinergic neurons in the MLR of lampreys has prompted us to investigate the possibility that muscarinic receptors also play a role in the control of locomotion. These receptors are present in the brainstem of many vertebrate species and modulate neuronal and synaptic properties (McCormick 1992; Bal et al. 1994; Klink and Alonso 1997a,b; Segal and Auerbach 1997). Interestingly, in several vertebrate species, muscarinic effects of acetylcholine were observed in the brainstem reticular formation (Barnes et al. 1987; Imon et al. 1996; Baghdoyan and Lydic 1999). Recently, a muscarinic depression of the startle reflex generated by RS cells was observed in mammals (Fendt et al. 2001).

The present study investigated a possible muscarinic modulation of synaptic responses of lamprey RS neurons to trigeminal sensory inputs. We show that the disynaptic postsynaptic potentials (PSPs) induced by trigeminal nerve stimulation display an atropine-sensitive depression after a local application of muscarinic agonists on the recorded RS cell or on trigeminal relay. The perfusion of muscarinic receptor antagonists produces an opposite effect, suggesting that a tonic muscarinic depression of trigeminal sensery inputs to RS neurons. Atropine also reduces the threshold for eliciting depolarizing plateaus in RS cells and increases cell discharge. The muscarinic inhibition is directed mainly against the NMDA component of glutamatergic responses, and under atropine perfusion intrinsic NMDA-induced oscillations are unmasked in RS neurons. 


\section{MATERIALS AND METHODS}

Experiments were performed in larval $(n=41)$ and young adult $(n=17)$ lampreys, Petromyzon marinus. Results from larval and adult animals were combined because no clear differences were observed. All procedures conformed to the guidelines of the Canadian Institutes for Health Research and were approved by the University Animal Care and Use Committee. Under tricaine methanesulphonate anesthesia (MS 222, $100 \mathrm{mg} / \mathrm{L}$, Sigma, Milwaukee, USA), the animals were incised along the ventral midline and eviscerated. The dissection and subsequent experiments were performed in cold Ringer's with the following composition (in mM): 130 $\mathrm{NaCl}, 2.1 \mathrm{KCl}, 2.6 \mathrm{CaCl}_{2}, 1.8 \mathrm{MgCl}_{2}$, 4 Hepes, 4 Dextrose, $1 \mathrm{NaHCO}_{3}$. The rostral end of the body up to the last gill was dissected, isolating the brain and spinal cord with the underlying cranium and notochord kept for support. The spinal cord was then cut at the level of the first segment (Fig. 1A) and the preparation was pinned down to the Sylgard bottom of an experimental chamber perfused with oxygenated cold Ringer's $\left(9^{\circ} \mathrm{C}\right.$; $\left.\mathrm{pH} 7.4\right)$. A semi-intact preparation $(\mathrm{n}=4)$ was also used, where the rostral end of the animal was dissected out as described above and pinned down to the Sylgard bottom of the experimental chamber, whereas the caudal two thirds of the body and the tail were left intact to swim freely behind in the Ringer's solution. For decerebration purposes, a complete transection was made either above or below (Fig. 1A) the mesencephalon. There was no difference in the responses to the local application of muscarinic agonists whether the mesencephalon was kept or not. During the course of the experiments, the brainstem was constantly perfused with Ringer's ( $2 \mathrm{ml} / \mathrm{min})$.

RS neurons in the middle (MRRN, $n=62)$ and posterior (PRRN, $n=3$ ) rhombencephalic reticular nuclei were impaled under visual inspection with sharp glass microelectrodes (4M K-acetate, $\sim 100 \mathrm{M} \Omega$; Fig. 1A). The recorded cells were the largest reticular neurons in these two reticular 
nuclei of the lamprey including the Müller cells in the MRRN (see Rovainen 1982). The signals were recorded with an Axoclamp 2A (Axon Instruments Inc., Foster City, CA) and directed to a computer (sampling rate: 2-10 kHz) through a TL-1 DMA interface (Axon Instruments Inc.). All neurons had a resting membrane potential (mean value: $-74.6 \pm 0.6 \mathrm{mV}$ ) that remained constant throughout the experiment. The effects of drug applications and trigeminal nerve stimulation were all tested at resting potential. Cell input resistance was estimated from the slope of the linear regression calculated on $\mathrm{I}-\mathrm{V}$ curves (current-voltage relationship built by injecting current steps of different amplitudes). Repetitive firing properties were studied by injecting depolarizing square-pulses (500 msec duration). The peak amplitude of the slow afterhyperpolarization (AHP) was measured from the action potential threshold. The area and the maximal amplitude of PSPs were measured after filtering the spikes in the few instances where the latter occurred. The area was measured from the beginning of the response until the membrane potential returned to the resting level. The peak amplitude was the difference between the resting membrane potential and the maximum of the depolarization except if specified otherwise (early and late components in Fig. 5). Spikes were truncated in Figs. 4, 9 and 10 in order to reduce space.

Electrical stimulation of either the ipsi- or the contralateral trigeminal sensory root (single shocks of $2 \mathrm{~ms}$ duration at $0.1 \mathrm{~Hz}$ ) was performed with a glass-coated tungsten microelectrode (4-5 M $\Omega$, either homemade or purchased from Micro Probe Inc., Potomoc, MD) using a Grass S88 stimulator (Grass Instrument Co., Quincy, MA). The trigeminal-evoked PSPs were monitored several minutes before and after drug applications (e.g., Fig. 1C). All drugs were purchased from Sigma-Aldrich (Oakville, ON). Some of the drugs were applied locally: small droplets $(0.5-10 \mathrm{~nL})$ of acetylcholine $(1 \mathrm{mM})$, pilocarpine $(1 \mathrm{mM})$, muscarine $(1 \mathrm{mM})$, atropine $(1 \mathrm{mM})$, scopolamine $(1 \mathrm{mM})$, N-methyl-D-aspartate (NMDA, 1 and $10 \mathrm{mM})$, or $( \pm)$-alpha- 
amino-3-hydroxy-5-methylisoxazole-4-propionic acid (AMPA, $1 \mathrm{mM}$ ), dissolved in freshlymade Ringer's, were pressure-applied locally (on the RS cells or the relay cell region) through a glass micropipette using a Picospritzer (General Valve Corporation, Fairfield, NJ; Fig. 1A). The inactive dye Fast Green was added to the drug mixture in order to monitor the size of the application and the wash out of the drug. Control ejections of Ringer's or Fast Green alone had no effects on the evoked PSPs. Atropine $(10 \mu \mathrm{M})$, strychnine $(4 \mu \mathrm{M})$, tetrodotoxin $(1 \mu \mathrm{M})$, and phosphonovaleric acid (AP5; $200 \mu \mathrm{M})$ were dissolved in the Ringer's solution and bath applied. Between each drug application, a wash out period was allowed for complete recovery, from 15 minutes to more than one hour depending on the drug and the application technique used.

Data in the text and figures are given as mean \pm SEM. The significance of changes in input resistance was assessed by the difference between the slopes. The statistical significance for differences between means was determined with paired Student's t-tests, using Origin software (OriginLab Corporation, Northampton, MA). 


\section{RESULTS}

\section{Muscarinic receptor-mediated modulation of the trigeminal inputs to RS neurons}

Under control conditions, single stimulation shocks to the trigeminal sensory root on one side (Fig. 1A) evoked large PSPs in RS neurons (see Viana Di Prisco et al. 1995) and the amplitude of the responses remained constant from one stimulus to the other. After a local pressure-application of acetylcholine $(1 \mathrm{mM})$ onto the recorded RS cell the PSPs were significantly depressed (Fig. 1B1). The cumulated data from ten RS neurons show that both the peak amplitude $(86 \pm 5 \% ; \mathrm{p}<0.05)$ and the area $(50 \pm 6 \% ; \mathrm{p}<0.01)$ of the trigeminal-evoked PSPs were reduced (Fig. 1B2). In most cases, the depression lasted for several tens of minutes (Fig. 1C). On the other hand, there was no significant long-lasting change in the RS cell input resistance $(105 \pm 2 \% ; \mathrm{p}>0.05 ; \mathrm{n}=8)$, except in two cells where a small but significant persistent increase occurred (e.g. Fig. 1C). This suggests that the PSP depression produced by a local ejection of acetylcholine does not result from changes in RS neuron conductance.

We previously showed that acetylcholine produces large depolarizations in lamprey RS neurons resulting from the activation of nicotinic receptors (Le Ray et al. 2003). However, nicotine ejection over RS cells never produced a long-lasting depression of the trigeminal-evoked PSPs (not illustrated), suggesting that muscarinic receptors may be involved. To test this, the muscarinic agonist pilocarpine $(1 \mathrm{mM})$ was applied locally onto the recorded RS neurons (Fig. 2; $\mathrm{n}=9$ ) and, similarly to acetylcholine, it depressed the trigeminal-evoked PSPs (Fig. 2Al). Both the peak amplitude $(75 \pm 16 \% ; \mathrm{p}<0.01)$ and the area $(76 \pm 26 \% ; \mathrm{p}<0.01)$ of the synaptic responses were reduced (Fig. 2A2). The effects lasted for more than 1 hour after washing out the drug (single experiment in Fig. 2B1: p<0.001; cumulated data in Fig. 2B2: $\mathrm{p}<0.01$ ). In contrast to the effects 
of acetylcholine, pilocarpine always increased $(130 \pm 13 \% ; \mathrm{p}<0.001 ; \mathrm{n}=4)$ the input resistance of RS neurons (Fig. $2 B 2$ and $C 2$ ), whereas there was no change in the membrane potential (Fig. 2C1), suggesting a possible effect on leak channels.

We examined whether there was a tonic cholinergic modulation of trigeminal inputs onto RS cells. A bath application of the muscarinic antagonist atropine $(10 \mu \mathrm{M}$; not illustrated) increased both the peak amplitude $(n=18 ; \mathrm{p}<0.05)$ and the area $(n=18 ; \mathrm{p}<0.05)$ of trigeminalevoked PSPs, but atropine did not affect the input resistance in the nine cells into which it was tested. Atropine $(1 \mathrm{mM})$ was then pressure ejected locally onto the recorded RS cell while the trigeminal nerve was stimulated. It significantly enhanced the PSPs area in 4 out of 15 RS cells (mean area of the 4 cells: $149 \pm 17 \%$ of the control; $\mathrm{p}<0.05$; Fig. $3 A 1-2$ ). There were no significant changes in the trigeminal-evoked PSPs in the other 11 cells. Neither the resting membrane potential nor the input resistance were changed by atropine ( $>>0.05$; Fig. 3B1-3). In preparations pre-incubated with atropine $(\mathrm{n}=2)$, a local application of acetylcholine failed to produce a depression of the trigeminal-evoked responses (not illustrated).

Because local applications of the muscarinic antagonist produced less reliable effects than those of bath applications, we investigated whether there was a muscarinic modulation of the trigeminal inputs at the level of the trigeminal relay cell. The interneurons relaying trigeminal inputs are located along the descending tract of the trigeminal nerve in the rhombencephalon (Northcutt, 1979; G Viana Di Prisco, D Petropoulos, T Boutin, F Brocard and R Dubuc, unpublished observations). Acetylcholine was pressure ejected over the region containing the relay cells (Fig. 4A1). This resulted in a depression of the trigeminal-evoked PSPs $(73 \pm 10 \%$; $\mathrm{p}<0.05$; n=4; Fig. 4A2, A3). There was no effect in the early part of the PSPs (see detail in Fig. 4A2). Similarly, there was a depression of the trigeminal-evoked PSPs without changes of 
their early part of the response after pressure ejecting either pilocarpine $(72 \pm 5 \%$; $<<0.05 ; n=3$; Fig. $4 B)$ or muscarine $(61 \pm 11 \% ; \mathrm{p}<0.05 ; \mathrm{n}=3$; not illustrated $)$ in the same region, suggesting that muscarinic receptors are involved in the depression. Note that the depression effect of muscarinic agonists ejected on trigeminal relay lasted for as long as when the agonists were ejected over RS cells. When atropine was applied over the region containing the trigeminal relay cells (Fig. 4C1), the area of the PSPs was greatly enhanced $(320 \pm 50 \%$; $<<0.001 ; n=6$; Fig. $4 C 3)$ to the point of generating multiple action potentials (see Fig. 4C2). However, the early part of the PSP remained unaffected (see detail Fig. 4C2). An increase in the area of the trigeminal-evoked PSPs (320 $\pm 29 \% ; \mathrm{p}<0.01 ; \mathrm{n}=4)$ also occurred when scopolamine was substituted for atropine in the ejection pipette (not illustrated). The effects of the muscarinic antagonists suggest that acetylcholine exerts a tonic depression of trigeminal inputs to RS cells through the activation of muscarinic receptors both at the relay site and at the level of RS cells in some cases.

\section{Cellular target of the muscarinic modulation}

Because trigeminal sensory inputs can consist of both glutamatergic EPSPs and glycinergic IPSPs (Viana Di Prisco et al. 1995), the muscarinic effects may have resulted from changes in inhibitory transmission. To test this, experiments $(n=5)$ were performed in the presence of strychnine $(4 \mu \mathrm{M})$. Similarly to the results obtained in control saline, atropine markedly increased the late part of the trigeminal-evoked EPSPs under strychnine $(317 \pm 57 \% ; \mathrm{p}<0.01 ; \mathrm{n}=5$; Fig. 5A1,B1). There was a small increase in the early part of the EPSPs, although this was not statistically significant (149 $\pm 20 \% ; \mathrm{p}>0.05 ; \mathrm{n}=5$; Fig. 5A2,B2), suggesting that strychnine could unmask an early excitation that is sensitive to muscarinic modulation. We did not pursue this further and additional experiments would be needed to test this hypothesis. Pilocarpine ejection was also tested on trigeminal-evoked EPSPs. There was a significant decrease in the peak 
amplitude of the early EPSPs $(69 \pm 5 \%$; $<<0.01 ; n=3$; not shown). These results suggest that there is a muscarinic modulation of the glutamatergic component of the trigeminal-evoked synaptic responses.

Atropine seemed to preferentially increase the late part of the trigeminal-evoked PSPs (Figs. 3 and $4 C$ ). This would be consistent with a modulatory effect on the NMDA component of the synaptic potentials. We further examined if the muscarinic modulation was exerted differently on the NMDA and the AMPA/kainate glutamatergic components of the trigeminal inputs to RS cells. The effects of the muscarinic drugs were thus tested after blocking the NMDA receptors. After adding AP5 $(200 \mu \mathrm{M})$ the area of the PSPs was markedly reduced in all 6 cells tested (18.6 $\pm 3.8 \%$ p $<0.01$; Fig. $6 A, B$ ), as previously described (Viana Di Prisco et al. 1995). In the presence of AP5, atropine did not increase the area of the trigeminal-evoked PSPs $(90 \pm 30 \% ; \mathrm{p}>0.05 ; \mathrm{n}=3$; Fig. $6 A 1-2)$ nor did pilocarpine reduce them significantly $(88.8 \pm 30 \%$; $>0.05 ; \mathrm{n}=3$; Fig. $6 B 1-2)$. These results suggest that the NMDA receptor-mediated component of the trigeminal-evoked responses in RS cells is the main target of the muscarinic modulation.

To determine whether the muscarinic modulation of the NMDA component occurred at the level of the RS neuron, the effects of atropine $(10 \mu \mathrm{M}$, bath-applied) were tested on the depolarizing responses elicited by local ejections of two glutamatergic agonists onto RS neurons (Fig. 7A-B). The non-NMDA agonist AMPA $(1 \mathrm{mM})$ evoked large depolarizations (Fig. 7Al, black trace) that were not affected by atropine (gray trace). Neither the peak amplitude ( $\mathrm{n}=12$; Fig. $7 A 2 ; p>0.05)$ nor the area $(p>0.05)$ of the depolarizing responses were modified, which confirmed that muscarinic modulation was not directed against non-NMDA responses. In contrast, the depolarizing responses evoked by a local ejection of $1 \mathrm{mM}$ NMDA (Fig. 7B1, black trace) were markedly enhanced in the presence of atropine (gray trace) such that both the peak 
amplitude $(167 \pm 25 \% ; \mathrm{p}<0.01)$ and the area $(220 \pm 56 \% ; \mathrm{p}<0.05)$ of the depolarizing responses were increased ( $\mathrm{n}=24 ;$ Fig. $7 B 2$ ). This suggests that at least a part of muscarinic modulation is exerted postsynaptically on the NMDA component of the excitation elicited in the target RS cells. It is noteworthy that the effects varied from one preparation to another. In 8 cases, atropine had little or no effect on the NMDA depolarization, whereas in the 16 other cases, there was a marked increase that reached a higher statistical significance $(\mathrm{p}<0.001)$. These differences could result from variable levels of endogenous release of acetylcholine in different preparations.

\section{Effects of muscarinic receptor activation on plateau potentials in RS cells}

Strong cutaneous stimulation induces depolarizing plateaus in RS neurons that are involved in the escape swimming in lampreys (Viana Di Prisco et al. 1997, 2000). We have examined whether the depolarizing plateaus were subjected to a muscarinic modulation. In all of the RS cells tested $(\mathrm{n}=5)$, a bath application of atropine $(10 \mu \mathrm{M}, 30-60 \mathrm{~min})$ enhanced the depolarization plateaus such that the area of the maximal responses was increased significantly on average to $544 \pm 84 \%$ with respect to the control in the 5 animals tested (p<0.01; Fig. 8A1-2). The threshold for inducing a depolarization plateau was also reduced to $50 \pm 25 \%$ of control value $(\mathrm{p}<0.05 ; \mathrm{n}=5)$. In 4 out of 5 experiments, atropine increased the firing rate for maximal responses to $258 \pm 19 \%$ of control $(\mathrm{p}<0.05 ; \mathrm{n}=5$; Fig. 8A3). Neither the input resistance nor the discharge properties measured with intracellular current injections were affected by atropine (Fig. 8B1-2; see also Fig. $3 C$ ). Moreover, there was no significant change in the peak amplitude of the slow AHP (mean values in control: $10.7 \pm 1.7$ vs. under atropine: $10.1 \pm 1.3 \mathrm{mV}$; $\mathrm{p}>0.05 ; \mathrm{n}=16$; e.g., Fig. $8 C$ ). It appears therefore that the increase in the firing rate results from an increase in the depolarization of the RS cell. 


\section{Intrinsic NMDA-evoked oscillations unmasked by atropine}

Because depolarizing plateaus largely depend on NMDA receptor activation (Viana Di Prisco et al. 1997, 2000) and atropine enhances the occurrence of such depolarizing plateaus (see above), we examined the impact of blocking muscarinic receptors on NMDA-induced plateau properties. Using a slightly leaking pipette (volume estimated at $<1 \mu \mathrm{L} \cdot \mathrm{min}^{-1}$ ), NMDA (1 mM) was applied for several tens of seconds on intracellularly recorded RS neurons (n=5; Fig. 9). In control Ringer's solution, NMDA generated a large amplitude depolarization accompanied by sustained firing, which adapted after some 75-100 s (Fig. 9A1). Then, the membrane potential of the recorded cell remained depolarized throughout the NMDA application (Fig. 9A1, and see detail in $A 2$ ). When $10 \mu \mathrm{M}$ atropine was added to the Ringer's solution (Fig. 9B1, and see detail in B2), membrane potential oscillations appeared on top of the NMDA-evoked depolarization, and spiking occurred on top of each oscillation during the whole duration of the NMDA-evoked oscillatory behavior (compare Fig. $9 A 1$ and 9B1). Moreover, NMDA still induced oscillations after adding $1 \mu \mathrm{M}$ tetrodotoxin to the atropine containing Ringer's solution (Fig. 9C1, C2), whereas NMDA-induced oscillations did not occur in the presence of tetrodotoxin alone (Fig. 9D1-2), suggesting that some RS neuron intrinsic properties were unmasked by the perfusion of the muscarinic antagonist.

Interestingly, the presence of oscillations in RS neurons did not require long lasting applications of NMDA as described above. Similar oscillations under atropine could also be observed in response to a single focal ejection of NMDA (1-10 mM) onto the recorded RS cells (n=13; e.g., Fig. 10A). Small oscillations of the membrane potential amplitude occurred when the RS neuron began to repolarize after a large NMDA-evoked depolarization (Fig. 10A2, top). There was then a slow increase in the amplitude of the oscillations, and action potentials were fired 
(Fig. 10A2, bottom). Similarly, a high frequency electrical stimulation (15 pulses, $30 \mathrm{~Hz})$ of a trigeminal nerve could trigger membrane potential oscillations in RS cells in the presence of atropine (e.g., Fig. 10B). Because such oscillations were observed in the isolated rhombencephalon $(n=6)$ in which the spinal cord was cut just below the PRRN, they could not result from ascending inputs conveyed by spino-reticular inputs from the locomotor networks (Dubuc and Grillner 1989; Vinay and Grillner 1993; Vinay et al. 1998). In a few preparations $(n=3)$ where the rhombencephalon was isolated from the rest of the CNS, oscillatory behavior in the form of repeated bursting could be observed in the absence of atropine, either in response to trigeminal sustained stimulation or 'spontaneously' in the presence of strychnine. Interestingly in each of these cases, a single focal ejection of pilocarpine $(2 \mathrm{mM})$ onto the recorded RS neuron was able to stop abruptly an ongoing burst and increase the time interval before the onset of the following bursts ( $\sim 70 \%$ increased delay; $\mathrm{p}<0.05 ; \mathrm{n}=5$; not illustrated). The addition of $10 \mu \mathrm{M}$ atropine prevented the effect of the focal ejection of pilocarpine ( $n=4$; not illustrated). 


\section{DISCUSSION}

Results from the present study show that there is a muscarinic modulation of the synaptic responses induced in RS cells by stimulation of trigeminal afferents. Muscarinic agonists depressed the trigeminal-evoked PSPs and muscarinic antagonists increased them. Atropine also potentiated the depolarizing responses induced by NMDA ejected on the recorded RS cell, but not that induced by AMPA. Atropine also unmasked membrane potential oscillations in response to either a local application of NMDA or stimulation of trigeminal afferents.

\section{Muscarinic modulation of the trigeminal glutamatergic sensory inputs}

There is evidence, in different vertebrate nervous systems, for a muscarinic modulation of glutamatergic responses (e.g., in rats: Jiang and Dun 1986; in cats: Andre et al. 1995). A muscarinic inhibition of glutamatergic responses was described in different regions of the CNS. In the spinal cord of neonate rats for example, acetylcholine induces an atropine-sensitive reduction of the sensory-evoked responses in motoneurons (Jiang and Dun 1986). Similarly, the non-selective cholinergic agonist carbachol produces an atropine-sensitive depression of the glutamatergic transmission in neurons (Marks and Roffwarg 1991; Metherate and Ashe 1995; Bellingham and Berger 1996; Sim and Griffith 1996). Likewise, muscarinic agonists such as oxotremorine (Lin and Phillis 1991) or muscarine, or the acetylcholinesterase inhibitor physostigmine (Bellingham and Berger 1996) induce a comparable inhibition of glutamatergic inputs in various neuronal structures. The activation of muscarinic receptors by acetylcholine in

pontine reticular giant neurons was proposed to be responsible for an inhibition of the startle reflexes induced by acoustic, visual or tactile stimuli (see Fendt et al. 2001). However, the mechanisms by which this inhibition is achieved are not understood. 
We now show that the trigeminal glutamatergic inputs to RS cells of lampreys are subjected to a powerful muscarinic modulation. These inputs are carried by a disynaptic pathway from trigeminal afferents to RS cells and thus, the muscarinic modulation could be exerted at different locations along the pathway. In the present study, we provide evidence that the modulation occurs at the level of both the reticulospinal cell and of the trigeminal relay. A local ejection of muscarinic agonists onto RS neurons reduced the trigeminal-evoked PSPs significantly. Interestingly, a local ejection of atropine enhances the synaptic responses in some of the RS cells, suggesting that, in the isolated brainstem preparation, there is tonic muscarinic depression of trigeminal inputs exerted at the level of the RS cell. The failure of atropine to potentiate the PSPs in some of these experiments when ejected over the recorded RS cell may result from either a variability of endogenous acetylcholine release among preparations or an absence of a significant activation of an NMDA component, the main substrate for the atropinemediated modulation (see below). Bath application of atropine on the other hand increased the trigeminal-evoked PSPs in all the cells tested. This prompted us to examine effects at the first synapse within this trigeminal pathway, that is at the level of the trigeminal relay.

In all cases tested, atropine ejected over the relay cells enhanced markedly the synaptic responses to trigeminal stimulation indicating that there was a strong muscarinic modulation also present at the level of the trigeminal relay in the brainstem. Local application of acetylcholine or selective muscarinic agonists over the trigeminal relay cells depressed the synaptic responses to trigeminal stimulation. Whether the modulation occurs presynaptically in primary afferent terminals or postsynaptically in the relay cells cannot be established yet. Presynaptic inhibition by muscarinic receptors activation was previously shown between primary afferents and lamina II neurons of rat spinal cord (see Li et al. 2002). 
In most of the cases reported in the literature to date, the muscarinic modulation of glutamatergic synapses has been found to rely on presynaptic mechanisms (Jiang and Dun 1986; Scanziani et al. 1995; Bellingham and Berger 1996; Smolders et al. 1997). We now provide evidence that the modulation occurs postsynaptically at least in part of the pathway. The response of RS cells to a local application of NMDA was potentiated by atropine perfusion. The increase was in the same range to that of the increase of the trigeminal-evoked PSPs by atropine (area: $+120 \pm 56 \%$ vs. $+101 \pm 70 \%$, and peak: $+67 \pm 25 \%$ vs. $+40 \pm 30 \%$, respectively). Because the atropine-induced changes in the response to NMDA local application persist under tetrodotoxin perfusion, it is likely that the effects occur postsynaptically at the level of the RS cell.

There are several lines of evidence, in the present study, indicating that the muscarinic modulation is predominantly exerted on the NMDA receptor-mediated component of the glutamatergic PSPs elicited by trigeminal stimulation: the depolarizing responses to direct application of NMDA onto the recorded RS cells were enhanced by atropine, whereas the responses to AMPA application were not; blocking NMDA receptors with AP5, abolished the effects of muscarinic agonists and antagonists on the trigeminal-evoked PSPs; muscarinic drug applications usually had little effect on the early part of the synaptic responses. Taken together these results suggest a predominant effect on the NMDA receptor-mediated component of the excitation. Although it is clear that there is a muscarinic modulation that occurs at the trigeminal relay, whether there is an effect on the NMDA receptors of the relay cells is not established yet. To address this issue, it will be necessary to record from the relay cells to examine the effects of muscarinic drugs on the monosynaptic response to primary afferent stimulation and on their responses to direct application of glutamatergic agonists. 
The mechanisms by which the activation of muscarinic receptors can modulate NMDA receptors remains to be determined in our preparation. Such mechanisms were examined in granule cell cultures (Courtney and Nicholls 1992). It was shown that NMDA receptors in granule cells are inhibited by phospholipase C-coupled muscarinic receptors. The AMPA/kainate receptors are not. The authors identified the second messenger pathway involved revealing a muscarinic protein kinase C-mediated inhibition of NMDA receptors. Because we also show a muscarinic effect on NMDA receptors and no effect on AMPA/kainate receptors in the lamprey system, it is thus possible that similar subcellular mechanisms are involved. Other studies have reported a postsynaptic modulation of a glutamatergic pathway by muscarinic receptors affecting either exclusively the AMPA/kainate subtype of glutamate receptors (Metherate and Ashe 1995) or both NMDA and non-NMDA receptor subtypes (Aramakis et al. 1997).

Whether the muscarinic modulation is specific to the trigeminal inputs to RS cells in the lamprey system remains to be established. Preliminary experiments in our lab indicate that a muscarinic modulation is also exerted on vestibular inputs to RS cells (AJOUTER UNE REF, unpublished). These results although preliminary, suggest that the modulation could be present in other sensory pathways.

\section{Muscarinic-induced changes of RS cell properties}

Muscarinic inputs were shown to induce oscillatory properties in various species. In the lobster for example, their perfusion on the stomatogastric neuronal network transforms passive neurons into spontaneously bursting neurons, which display plateau properties that are responsible for the neuron oscillatory behavior (Bal et al. 1994). Similarly in the rat, carbachol induces in the non-stellate neurons of the entorhinal cortex an atropine-sensitive bursting behavior that relies on an increase in intracellular calcium concentration (Klink and Alonso 
1997a,b), and voltage-dependent plateau properties in subicular neurons (Kawasaki et al. 1999). In lamprey RS neurons, intrinsic plateau potential and bursting properties are revealed by the bath perfusion of the muscarinic antagonist atropine. This suggests that, in this system, as in dorsolateral geniculate neurons of cats and guinea pigs (McCormick 1992), the activation of muscarinic receptors would block endogenous bursting properties.

More than twenty years ago, NMDA-induced oscillations were described in interneurons and motoneurons of the lamprey spinal cord (Sigvardt and Grillner 1981; Sigvardt et al. 1985). The oscillations were shown to be intrinsic to the spinal neurons, as they persisted in the presence of TTX. We show that similar oscillations can occur in brainstem RS cells of lampreys, but only after blocking muscarinic receptors. In the absence of muscarinic antagonists, only long-lasting depolarization plateaus are evoked by NMDA. The mechanism by which the oscillations occur in RS cells is unknown at this stage. If RS cells of lampreys were to display similar mechanisms than granules cells (Courtney and Nicholls 1992) it is possible that NMDA receptors would be tonically inhibited by muscarinic receptors and that adding the muscarinic antagonist, atropine, removes this tonic inhibition. Oscillations could then be unmasked in the presence of NMDA.

Si je peux me permettre une remarque, cette dernière partie en jaune, c'est un peu du vent. Ça n'explique et même ne discute absolument rien, et surtout pas comment les oscillations sont générées. C'est évident qu'elles ont dues au NMDA puisqu'elles n'apparaissent que sous stimulation NMDA. D'autre part, on a aussi montré que la composante NMDA est sous contrôle muscarinique tonique et que l'atropine démasque les oscillations (surtout qu'on le dit texto juste en dessous!!!!); donc ça n'a rien d'une hypothèse. Mais enfin, si ça vous convient comme cela... 


\section{Functional considerations}

The muscarinic antagonist atropine disclosed intrinsic oscillation properties underlying a bursting behavior in lamprey RS neurons in response to NMDA stimulation. To our knowledge, this is the first demonstration of such a property in RS neurons. The requirement of atropine for repetitive bursts to occur in response to a transient NMDA stimulation suggests that those oscillatory properties are tonically inhibited. A tonic muscarinic modulation was also reported in rat cortical neurons (Metherate and Ashe 1995; Hess and Krawczyk 1996). The origin of this tonic modulation remains unknown in lamprey RS cells. Nevertheless, in higher vertebrates (for a review see Fendt et al. 2001), cholinergic inputs projecting from both the pedunculopontine nucleus and the laterodorsal tegmentum to the reticular formation play a major role in the inhibition of startle responses. Because both of these brainstem regions contain cholinergic neurons and were recently described as part of the functionally defined MLR of lampreys (Pombal et al. 2001; Le Ray et al. 2003), the MLR could thus be the origin of the muscarinic modulation of RS cells.

The MLR is involved in goal-directed locomotion (for a review see Jordan 1998) and a muscarinic control originating from that region could provide a fine tuning of the weight of sensory inputs to the RS system during complex motor behaviors. This would prevent inadequate reflex responses to perturb the MLR locomotor command. Such a muscarinic modulation of sensorimotor integration originating from the MLR exerts a prepulse inhibition of startle reflexes in pontine reticulospinal cells (see Fendt et al. 2001). Furthermore, goal-directed locomotion requires a fine control from higher structures on $\mathrm{RS}$ command neurons that may be incompatible with a strong RS neuron activity such as a self-generated oscillatory behavior. Then, we can hypothesize that the MLR would silence such sensory-triggered intrinsic properties, and this 
through the activation of muscarinic receptors on RS neurons (and probably also on relay interneurons). In contrast, sensory-evoked locomotor activity (such as an escape reaction) does not require higher brain centers (Cardin et al. 1999). In this case, an oscillatory behavior generated at the RS level may, first, allow a sustained command onto spinal CPGs (since the oscillations permit a stronger firing than a single long duration plateau) and, second, reinforce the spinal-generated rhythm. This would presume the presence of mechanisms that regulate the cholinergic inputs from the MLR to RS cells in different behavioral contexts.

In lampreys, we recently demonstrated the role of nicotinic receptor-mediated cholinergic inputs to RS neurons in the initiation and the control of the MLR-evoked locomotion (Le Ray et al. 2003). In the light of these results and the present ones, we propose that the MLR could send a dual cholinergic "command" to RS neurons. Firstly, an excitatory command, mediated by nicotinic receptors would activate precisely the RS system and trigger complex motor behaviors (such as exploratory behavior or prey attack). Secondly, an inhibitory command mediated by muscarinic receptors would be sent in parallel to reduce sensory transmission both at the first relay and at the level of RS cells. The cholinergic inputs would thus be responsible for a shift of RS neurons from a "reflex locomotor command" to "goal-directed locomotor command" state. 


\section{REFERENCES}

Andre P, Pompeiano O, and White SR. Role of muscarinic receptors in the cerebellar control of the vestibulospinal reflex gain: cellular mechanisms. Acta Otolaryngol Suppl 520 Pt 1: 8791, 1995.

Aramakis VB, Bandrowski AE, and Ashe JH. Activation of muscarinic receptors modulates NMDA receptor-mediated responses in auditory cortex. Exp Brain Res 113: 484-496, 1997.

Baghdoyan HA, and Lydic R. M2 muscarinic receptor subtype in the feline medial pontine reticular formation modulates the amount of rapid eye movement sleep. Sleep 22: 835-847, 1999.

Bal T, Nagy F, and Moulins M. Muscarinic modulation of a pattern-generating network: control of neuronal properties. J Neurosci 14: 3019-3035, 1994.

Barnes CD, D'Ascanio P, Pompeiano O, and Stampacchia G. Effects of microinjection of cholinergic agonists into the pontine reticular formation on the gain of vestibulospinal reflexes in decerebrate cats. Arch Ital Biol 125: 71-105, 1987.

Bellingham MC, and Berger AJ. Presynaptic depression of excitatory synaptic inputs to rat hypoglossal motoneurons by muscarinic M2 receptors. J Neurophysiol 76: 3758-3770, 1996.

Brocard F, and Dubuc R. Differential contribution of reticulospinal cells to the control of locomotion induced by the mesencephalic locomotor region. J Neurophysiol 90: 1714-1727, 2003.

Bussières N, and Dubuc R. Phasic modulation of transmission from vestibular inputs to reticulospinal neurons during fictive locomotion in lampreys. Brain Res 582: 147-153, 1992.

Cardin, S., Le Ray, D. Robitaille, R. and Dubuc, R. Motor responses elicited by skin stimulations in lampreys. Soc. Neurosci. Abstr. 25: 1906, 1999. 
Clarac F. How do sensory and motor signals interact during locomotion? In: Motor Control: Concepts and Issues, edited by Humphrey DR, and Freund HJ. New York: Wiley, 1991, pp. 199-221.

Courtney MJ, and Nicholls DG. Interactions between phospholipase C-coupled and $N$-methylD-aspartate receptors in cultured cerebellar granule cells: protein kinase $\mathrm{C}$ mediated inhibition of $N$-methyl-D-aspartate responses. J. Neurochem 59: 983-992, 1992.

Deliagina T, Ullén F, Gonzalez M, Ehrsson H, Orlovsky G, and Grillner S. Initiation of locomotion by lateral line photoreceptors in lamprey: behavioural and neurophysiological studies. J Exp Biol 198: 2581-2591, 1995.

Dubuc R, Bongianni F, Ohta Y, and Grillner S. Anatomical and physiological study of brainstem nuclei relaying dorsal column inputs in lampreys. J Comp Neurol 327: 260-270, 1993a.

Dubuc R, Bongianni F, Ohta Y, and Grillner S. Dorsal root and dorsal column mediated synaptic inputs to reticulospinal neurons in lampreys: involvement of glutamatergic, glycinergic, and GABAergic transmission. J Comp Neurol 327: 251-269, $1993 \mathrm{~b}$.

Dubuc R, Cabelguen JM, and Rossignol S. Dorsal root potentials and antidromic discharges of primary afferents during fictive locomotion in the cat. In: Neurobiology of vertebrate locomotion, edited by Grillner S, Forssberg H, Stein PSG, and Stuart D. London: MacMillan, 1986, pp. 535-538.

Dubuc R, and Grillner S. The role of spinal cord inputs in modulating the activity of reticulospinal neurons during fictive locomotion in the lamprey. Brain Res 483: 196-200, 1989. 


\section{Dunean-CJ,and Publicover SJ. Inhibity effect}

I

El Manira A, Pombal MA and Grillner S. Diencephalic projection to reticulospinal neurons involved in the initiation of locomotion in adult lampreys Lampetra fluviatilis. J Comp Neurol 389: 603-616, 1997a.

EI Manira A, Tegner J, and Grillner S. Locomotor-related presynaptic modulation of primary afferents in the lamprey. Eur J Neurosci 9: 696-705, $1997 \mathrm{~b}$.

Fendt M, Li L, and Yeomans JS. Brain stem circuits mediating prepulse inhibition of the startle reflex. Psychopharmacology (Berl) 156: 216-224, 2001.

Gossard JP, Cabelguen JM, and Rossignol S. Intra-axonal recordings of cutaneous primary afferents during fictive locomotion in the cat. J Neurophysiol 62: 1177-1188, 1989.

Grillner S, Wallén,P,HillR, Gangiano-G,and EHManimaA. I

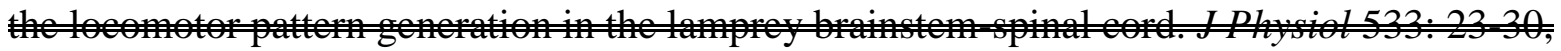
2001.

Hess G, and Krawczyk R. Cholinergic modulation of synaptic transmission in horizontal connections of rat motor cortex. Acta Neurobiol Exp 56: 863-872, 1996.

Imon H, Ito K, Dauphin L, and McCarley RW. Electrical stimulation of the cholinergic laterodorsal tegmental nucleus elicits scopolamine-sensitive excitatory postsynaptic potentials in medial pontine reticular formation neurons. Neuroscience 74: 393-401, 1996.

Jiang ZG, and Dun NJ. Presynaptic suppression of excitatory postsynaptic potentials in rat ventral horn neurons by muscarinic agonists. Brain Res 381: 182-186, 1986.

Jordan LM. Initiation of locomotion in mammals. Ann NY Acad Sci 860: 83-93, 1998. 
Kawasaki H, Palmieri C, and Avoli M. Muscarinic receptor activation induces depolarizing plateau potentials in bursting neurons of the rat subiculum. J Neurophysiol 82: 2590-2601, 1999.

Klink R, and Alonso A. Ionic mechanisms of muscarinic depolarization in entorhinal cortex layer II neurons. J Neurophysiol 77: 1813-1828, 1997a.

Klink R, and Alonso A. Muscarinic modulation of the oscillatory and repetitive firing properties of entorhinal cortex layer II neurons. J Neurophysiol 77: 1813-1828, $1997 \mathrm{~b}$.

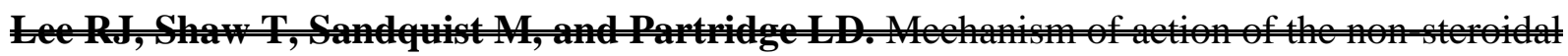
ati-fla y 19:431-138, 1996.

Le Ray D, Brocard F, Bourcier-Lucas C, Auclair F, Lafaille P, and Dubuc R. Nicotinic activation of reticulospinal cells involved in the control of swimming in lampreys. Eur $J$ Neurosci 17: 137-148, 2003.

Le Ray D, and Cattaert D. Active motor neurons potentiate their own sensory inputs via glutamate-induced long-term potentiation. J Neurosci 19: 1473-1483, 1999.

Li D-P, Chen S-R, Pan Y-Z, Levey AI, and Pan H-L. Role of presynaptic muscarinic and GABAB receptors in spinal glutamate release and cholinergic analgesia in rats. $J$ Physiol 543: 807-818, 2002.

Lin Y, and Phillis JW. Muscarinic agonist oxotremorine-M-induced long-term depression in rat cerebral cortex. Brain Res Bull 27: 115-117, 1991.

Marks GA, and Roffwarg HP. Cholinergic modulation of responses to glutamate in the thalamic reticular nucleus of the anesthetized rat. Brain Res 557: 48-56, 1991. 
McCormick DA. Cellular mechanisms underlying cholinergic and noradrenergic modulation of neuronal firing mode in the cat and guinea pig dorsal lateral geniculate nucleus. J Neurosci 12: 278-289, 1992.

Metherate R, and Ashe JH. Synaptic interactions involving acetylcholine, glutamate, and GABA in rat auditory cortex. Exp Brain Res 107: 59-77, 1995.

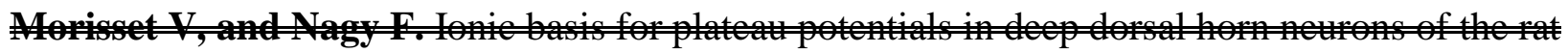
19:7309-7316,1999.

Northcutt RG. Experimental determination of the primary trigeminal projections in lampreys. Brain Res 163(2): 323-7, 1979.

Orlovsky GN, Deliagina TG, and Wallén P. Vestibular control of swimming in lamprey. I. Responses of reticulospinal neurons to roll and pitch. Exp Brain Res 90: 479-488, 1992.

Partridge LD, andValenzuela CF. Block hippeampalCAN hamels by flufenamate. Brain R67: 143-148, 2000.

Pombal MA, Marin O, and Gonzalez A. Distribution of choline acetyltransferaseimmunoreactive structures in the lamprey brain. J Comp Neurol 431: 105-126, 2001.

Rossignol S. Neural control of stereotypic limb movements. In: Handbook of Physiology, Section 12. Exercise: Regulation and Integration of Multiple Systems, edited by Rowell LB, and Sheperd JT. New York: Oxford University Press, 1996, pp. 173-216.

Rovainen CM. Neurophysiology. In: The Biology of Lampreys, volume 4A, edited by Hardisty MW, and Potter IC. London: Academic Press, 1982, pp. 1-136.

Scanziani M, Gahwiler BH, and Thompson SM. Presynaptic inhibition of excitatory synaptic transmission by muscarinic and metabotropic glutamate receptor activation in the hippocampus: are Ca2+ channels involved? Neuropharmacology 34: 1549-1557, 1995. 
Segal M, and Auerbach JM. Muscarinic receptors involved in hippocampal plasticity. Life Sci 60: 1085-1091, 1997.

Sillar KT, and Skorupski P. Central input to primary afferent neurons in crayfish, Pacifastacus leniusculus, is correlated with rhythmic motor output of thoracic ganglia. J Neurophysiol 55: 678-688, 1986.

Sim JA, and Griffith WH. Muscarinic inhibition of glutamatergic transmission onto rat magnocellular basal forebrain neurons in a thin-slice preparation. Eur J Neurosci 8: 880-891, 1996.

Sirota M, Viana Di Prisco G, and Dubuc R. Stimulation of the mesencephalic locomotor region elicits controlled swimming in semi-intact lampreys. Eur J Neurosci 12: 4081-4092, 2000.

Sigvardt KA, and Grillner S. Spinal neuronal activity during fictive locomotion in the lamprey. Soc Neurosci Abstr 7: 362, 1981.

Sigvardt KA, Grillner S, Wallén P, and van Dongen PA. Activation of NMDA receptors elicits fictive locomotion and bistable membrane properties in the lamprey spinal cord. Brain Res 336: 390-395, 1985.

Smolders I, Bogaert L, Ebinger G, and Michotte Y. Muscarinic modulation of striatal dopamine, glutamate, and GABA release, as measured with in vivo microdialysis. J Neurochem 68: 1942-1948, 1997.

Viana Di Prisco G, Ohta Y, Bongianni F, Grillner S, and Dubuc R. Trigeminal inputs to reticulospinal neurones in lampreys are mediated by excitatory and inhibitory amino acids. Brain Res 695:7 6-80, 1995. 
Viana Di Prisco G, Pearlstein E, Le Ray D, Robitaille R, and Dubuc R. A cellular mechanism for the transformation of a sensory input into a motor command. $J$ Neurosci 20 : 8169-8176, 2000.

Viana Di Prisco G, Pearlstein E, Robitaille R, and Dubuc R. Role of sensory-evoked NMDA plateau potentials in the initiation of locomotion. Science 278: 1122-1125, 1997.

Vinay L, Bussières N, Shupliakov O, Dubuc R, and Grillner S. Anatomical study of spinobulbar neurons in lampreys. J Comp Neurol 397: 475-92, 1998.

Vinay L, and Grillner S. The spino-reticulo-spinal loop can slow down the NMDA-activated spinal locomotor network in lamprey. Neuroreport 4: 609-612, 1993.

Zompa IC, and Dubuc R. A mesencephalic relay for visual inputs to reticulospinal neurones in lampreys. Brain Res 718: 221-227, 1996. 


\section{FIGURE LEGENDS}

Figure 1: Effects of acetylcholine on the trigeminal-evoked PSPs in RS neurons. A: Diagram of the in vitro rhombencephalic preparation. Electrical stimulation was applied to a sensory root of a trigeminal nerve (Trig. St) and acetylcholine (ACh, $1 \mathrm{mM}$ ) was locally ejected onto an intracellularly recorded RS neuron (here in the MRRN). B1: Superimposition of mean trigeminalevoked EPSPs (averages of three traces each) in control (black) and after acetylcholine local application (gray) at RS neuron resting potential $\left(\mathrm{V}_{\mathrm{R}}=-75 \mathrm{mV}\right)$. B2: Relative decrease in the EPSP peak amplitude (two bars in the left) and area (two bars in the right) after single acetylcholine ejection. *: $\mathrm{p}<0.05$; **: $\mathrm{p}<0.01$, data cumulated from 10 neurons. $C$ : Time course (relative to control value) of the EPSP area (squares) and cell input resistance (circles) after a single acetylcholine ejection. Single experiment. The $p$ value indicates the significance of the difference between control and test EPSPs. The significant changes in input resistance were evaluated on I-V curve slopes and are indicated by stars: $* * * \mathrm{p}<0.001$ and $* * \mathrm{p}<0.01$.

Figure 2: Effects of pilocarpine on the trigeminal-evoked PSPs in RS neurons. Al: Superimposition of trigeminal-evoked (Trig. St) mean EPSPs (averages of three traces each) in an RS neuron in control (black) and after single local application of $1 \mathrm{mM}$ pilocarpine (Pilo; gray) onto the recorded RS cell $\left(\mathrm{V}_{\mathrm{R}}=-75 \mathrm{mV}\right)$. A2: Relative decrease of the EPSP peak amplitude and area after single pilocarpine ejection (gray bars). ${ }^{* *}: \mathrm{p}<0.01$, data cumulated from 9 neurons. $B 1$ : Time course (relative to control value) of the EPSP area in a single experiment after single pilocarpine ejection. $B 2$ : cumulated results $(\mathrm{n}=4)$ showing both the EPSP area (squares) and the input resistance (circles) after single pilocarpine ejection. The significance of differences between 


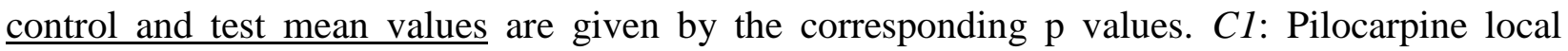
pressure ejections failed to evoke responses from an $R S$ neuron at resting potential $\left(V_{R}=-76 \mathrm{mV}\right)$. C2:Current-voltage relationship before (empty circles) and after (filled circles) application of pilocarpine.

Figure 3: Effect of atropine on trigeminal-evoked PSPs at the RS cell level. A: Atropine enhances the trigeminal-evoked EPSP in RS neurons. A1: Superimposed trigeminal-evoked (Trig. St) mean EPSPs (averages of three traces each) recorded from an RS neuron $\left(V_{R}=-75 \mathrm{mV}\right)$ in control (black) and after local application of $1 \mathrm{mM}$ atropine (gray) onto the recorded RS cell. A2: Histogram of the mean area of the sensory-evoked EPSPs in control (black bars) and under atropine (gray bars). $* \mathrm{p}<0.05$, data cumulated from four neurons. B: Lack of effect of atropine on RS neuron input resistance. B1: Sample recordings of voltage deviation in response to current intracellular injection in control (left) and after atropine local ejection (right). B2: Current-voltage relationship in control (black) and under atropine (gray). B3: Cumulated histogram illustrating the lack of effect of either a local ejection $(n=4)$ or a bath application $(n=9)$ of atropine (gray bar) on RS neurons input resistance. *: $\mathrm{p}<0.05$.

Figure 4: Effects of acetylcholine, pilocarpine and atropine on trigeminal-evoked PSPs at the second-order trigeminal neurons level. A: Pressure ejection of $1 \mathrm{mM}$ acetylcholine over the trigeminal relay cells reduced the sensory-evoked EPSPs. A1: The size of the ejection is illustrated on a schematized brainstem. A2: Superimposition of mean trigeminal-evoked EPSPs (averages of three traces each) in control (black) and after acetylcholine application (gray), $\mathrm{V}_{\mathrm{R}}=-76 \mathrm{mV}$. The peak amplitude of early EPSP (arrowhead and detail) was not affected. A3: 
Relative decrease of the EPSP area after acetylcholine ejection (gray bars, $\mathrm{n}=4$ cells). $B$ : Pressure ejection of $1 \mathrm{mM}$ pilocarpine over the trigeminal relay cells reduced the sensory-evoked EPSPs. B1: The size of the ejection is illustrated on a schematized brainstem. B2: Superimposition of mean trigeminal-evoked EPSPs (averages of three traces each) in control (black) and after pilocarpine (Pilo) application (gray), $\mathrm{V}_{\mathrm{R}}=-77 \mathrm{mV}$. The peak amplitude of early EPSP (arrowhead and detail) was not affected. B3: Relative decrease of the EPSP area after pilocarpine ejection (gray bars, $\mathrm{n}=3$ cells). $C$ : Pressure ejection of $1 \mathrm{mM}$ atropine over the trigeminal relay cells enhanced the sensory-evoked EPSPs. Cl: The size of the ejection is illustrated on a schematized brainstem. C2: Superimposition of mean trigeminal-evoked EPSPs (averages of trhee traces each) in control (black) and after pilocarpine application (gray), $V_{R}=-74 \mathrm{mV}$. The peak amplitude of early EPSP (arrowhead and detail) was not affected. Because under atropine the neuron usually developed a plateau that lasted several tens of seconds, the trace has been truncated for reason of space. C3: Relative increased of the EPSP area after atropine ejection (gray bars, $\mathrm{n}=6$ cells). $*: \mathrm{p}<0.05 ; * * *: \mathrm{p}<0.001$

Figure 5: Effect of atropine on trigeminal-evoked EPSPs, after a blockade of the glycinergic

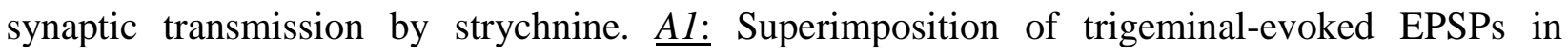
strychnine Ringers (black) and in strychnine after adding atropine (gray) at resting potential $\left(\mathrm{V}_{\mathrm{R}}=-\underline{74} \mathrm{mV}\right) . \underline{A 2}$ : Expanded time scale of $A l$ illustrating the changes occurring in the peak of the early component of the EPSP (arrowhead) measured $150 \mathrm{~ms}$ after the trigeminal stimulation. $\underline{B 1}$ : Cumulative histograms of the relative amplitude of the late part of the EPSP in strychnine (black bars) and in strychnine after adding atropine (gray bars). $*_{*} \mathrm{p}<0.01$, data cumulated from 5 
neurons. B2: Same as $B 1$ but with the amplitude of the early response (measured $150 \mathrm{~ms}$ after the trigeminal stimulation).

Figure 6: Effects of atropine and pilocarpine on trigeminal-evoked EPSP, after a blockade of NMDA receptors with AP5. $A 1$ and B1: Superimposition of mean trigeminal-evoked EPSPs in three conditions: control, in the presence of AP5 alone and in the presence of AP5 with atropine (A1) or pilocarpine $(B 1)$. Shaded area in $B 1$ indicate parts of the recordings shown at a higher magnification in the inset. Pharmacological isolation of the early EPSP with AP5 revealed no effect of atropine or pilocarpine. $A 2$ and $B 2$ : Histograms depicting the mean area of the EPSP in control, in the presence of AP5 alone and in the presence of AP5 with atropine (Al) or pilocarpine $(B 1)$. Areas were normalized to those in the control superfusate. $*: \mathrm{p}<0.05$; ***: $\mathrm{p}<0.001$.

La légende ne correspond pas à la figure que j'ai mais je suppose que vous l'avez changée...

Figure 7: Effects of a muscarinic receptor antagonist on the local ejection of glutamatergic agonists. A: Lack of effect of atropine on AMPA-evoked depolarization. A1:Superimposition of $1 \mathrm{mM}$ AMPA-evoked depolarizations in control (black) and in the presence of $10 \mu \mathrm{M}$ atropine (gray) at resting potential $\left(\mathrm{V}_{\mathrm{R}}=-75 \mathrm{mV}\right)$. A2: Cumulative histograms of the peak amplitude and area of the AMPA-evoked depolarization in control (black bar) and under atropine bath perfusion (gray bar). Data cumulated from 12 neurons. B: Atropine enhances depolarization evoked by NMDA local application. B1: Superimposition of $1 \mathrm{mM}$ NMDA-evoked depolarizations in control (black) and in the presence of atropine (gray) at resting potential $\left(\mathrm{V}_{\mathrm{R}}=-75 \mathrm{mV}\right)$. B2: Cumulative histograms of the peak amplitude and area of the NMDA-evoked depolarization in 
control (black bar) and under atropine bath perfusion (gray bar). *: $\mathrm{p}<0.05$; **: $\mathrm{p}<0.01$, data cumulated from 24 neurons.

Figure 8: Facilitation of sustained depolarizations by atropine. Al: Responses in RS neuron $\left(\mathrm{V}_{\mathrm{R}}=-75 \mathrm{mV}\right)$ to trigeminal nerve stimulation delivered at two distinct intensities in control and in the presence of atropine $(10 \mu \mathrm{M})$. Note that in control, stronger stimulation induced plateau potential sometimes accompanied by locomotor-related EPSPs (arrowheads) in a semi-intact preparation. A1: Plot of the stimulus intensity-response area relationship in a representative RS cell before (squares) and during bath perfusion of atropine (gray triangles). A2: Mean firing rate, determined from instantaneous frequency spikes during plateau potential in control (black) and under atropine (gray), in five RS cells from five experiments. **: $\mathrm{p}<0.01$; ***: $\mathrm{p}<0.001 . B 1$ : Lack of effect of atropine on spike-frequency discharge $\left(\mathrm{V}_{\mathrm{R}}=-74 \mathrm{mV}\right)$. B2: Spiking was examined by injecting $500 \mathrm{~ms}$ current pulses of increasing intensity. $C$ : Lack of effect of atropine on the slow AHP recorded at resting potential $\left(\mathrm{V}_{\mathrm{R}}=-73 \mathrm{mV}\right)$.

Figure 9: Atropine disclosed NMDA-induced oscillations. A1: RS neuron response to a continuous application of a small quantity of $1 \mathrm{mM}$ NMDA in normal Ringer's. A2: Detail of the boxed area in $A 1 . B 1$ : RS neuron response to the same NMDA stimulation in $10 \mu \mathrm{M}$ atropine bath perfusion. B2: Detail of the boxed area in $B 1 . C 1$ : RS neuron response of the same NMDA stimulation during the bath perfusion of $10 \mu \mathrm{M}$ atropine and $1 \mu \mathrm{M}$ tetrodotoxin. $C 2$ : Detail of the boxed area in $C 1 . A, B, C$ : same cell $\left(\mathrm{V}_{\mathrm{R}}=-70 \mathrm{mV}\right) . D 1$ : Under tetrodotoxin alone, no NMDA oscillations were observed. D2: Detail of boxed area in $D 1$.

D: Ça non plus je ne l'ai pas. 
Figure 10: Variability of the NMDA-induced oscillations under atropine bath perfusion. Al: Response to single NMDA application under atropine $\left(\mathrm{V}_{\mathrm{R}}=-80 \mathrm{mV}\right)$. A2: Detailed view of the boxed areas in $A 1$ showing the initial oscillatory rhythm (top) and the later established oscillatory behavior that allowed prolonged spike firing (bottom).

Il faudrait alors transformer les parties en A et B au lieu de A1 et A2. 
Figure 1
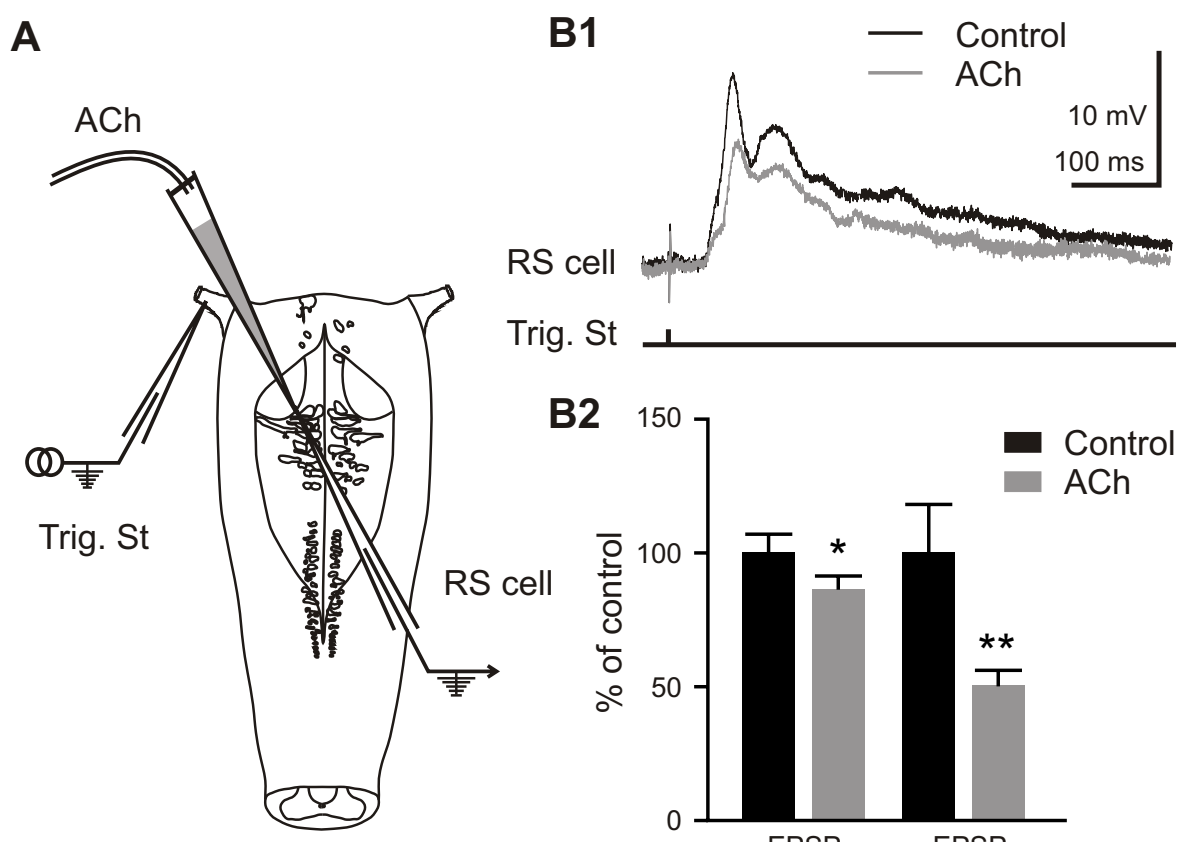

B2
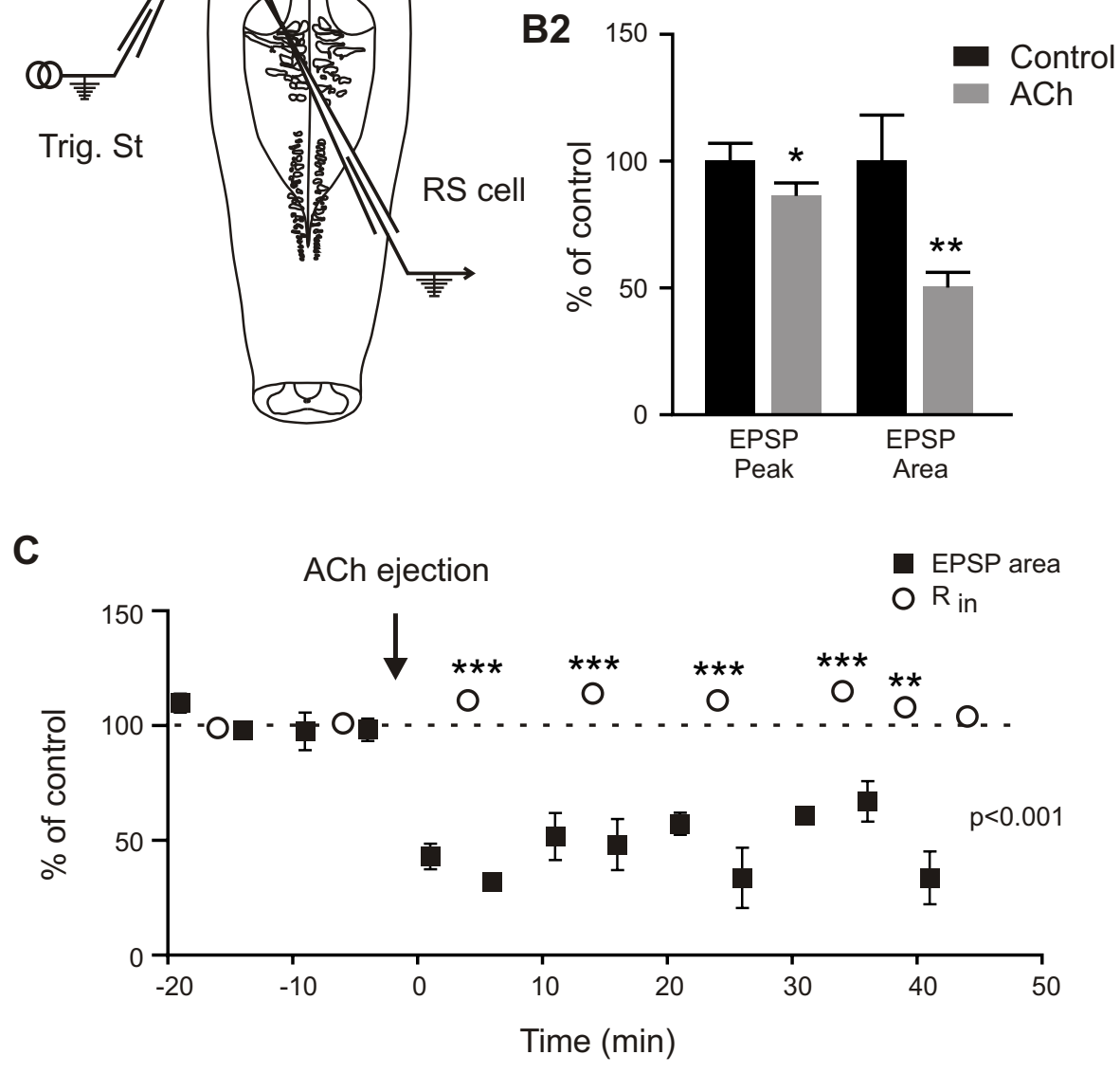


\section{Le Ray, Brocard \& Dubuc}

Figure 2

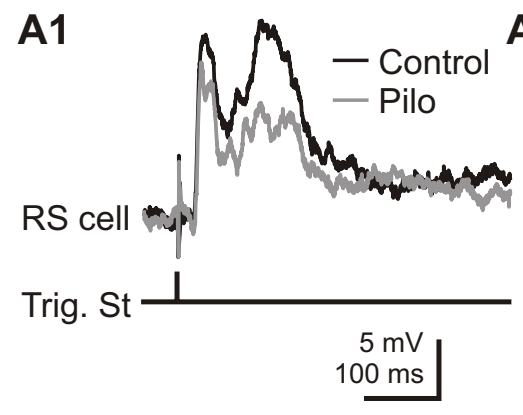

$\mathbf{B}^{200}$ Pilo ejection
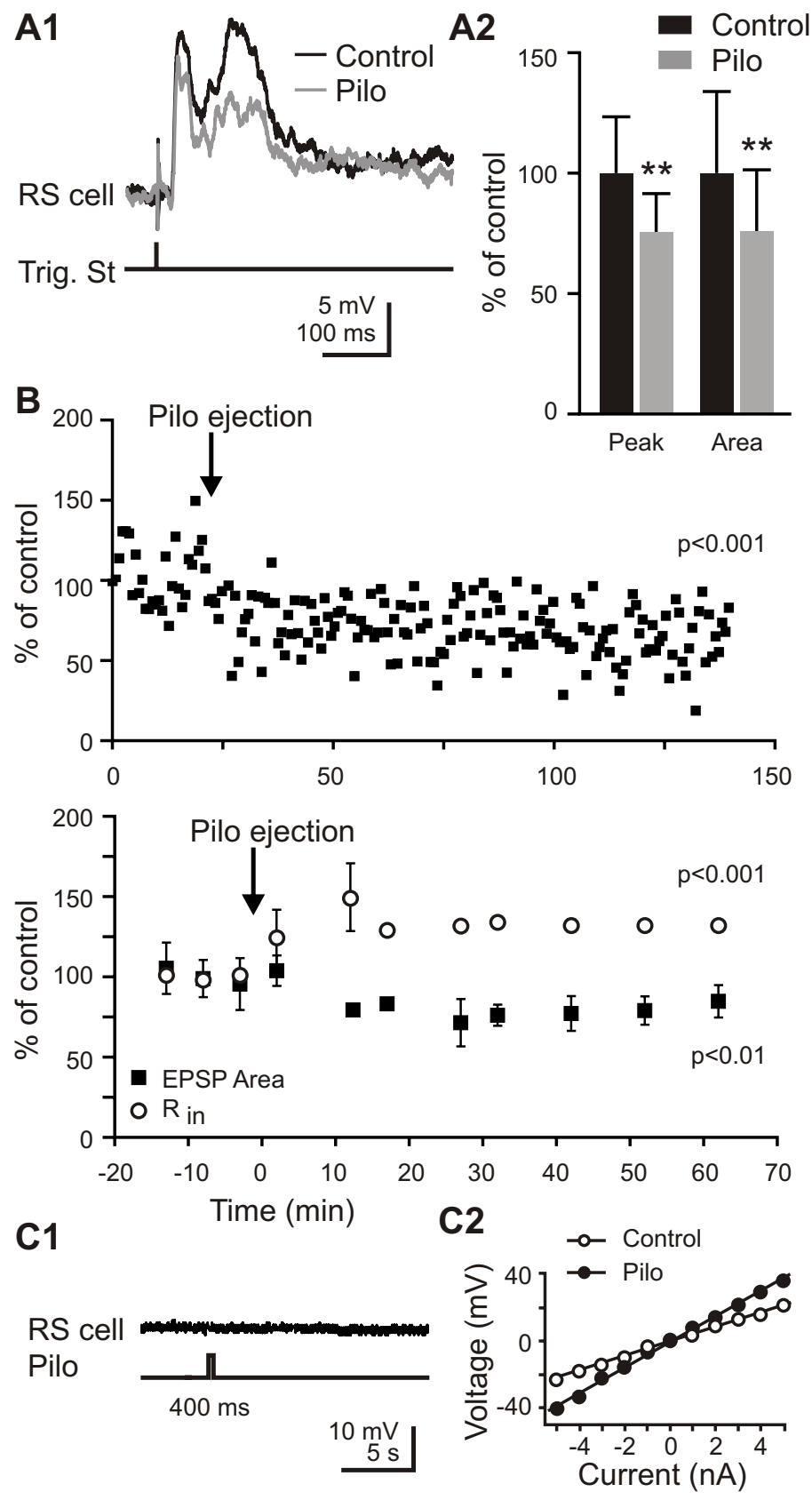


\section{Le Ray, Brocard and Dubuc}

Figure 3

A1

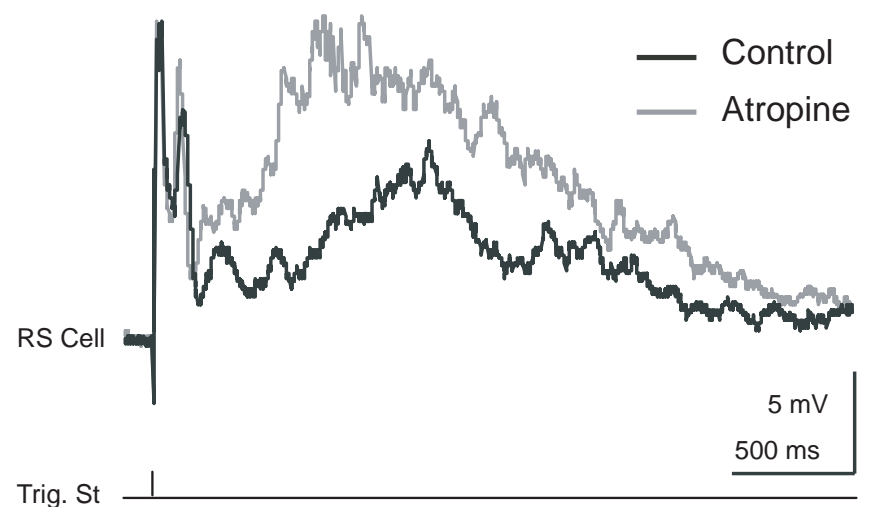

\section{A2}

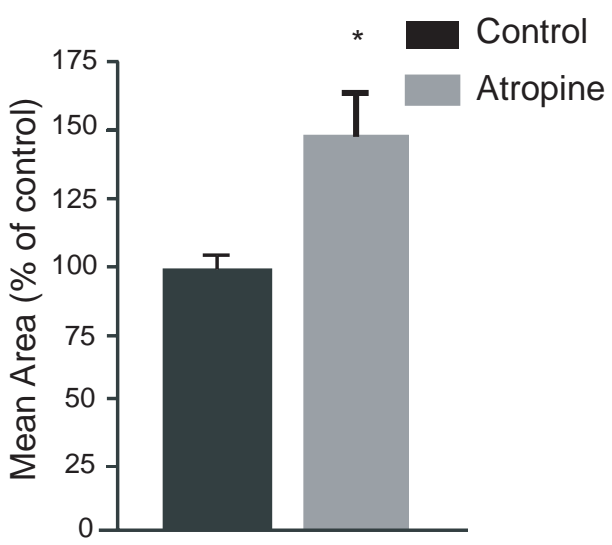

B1
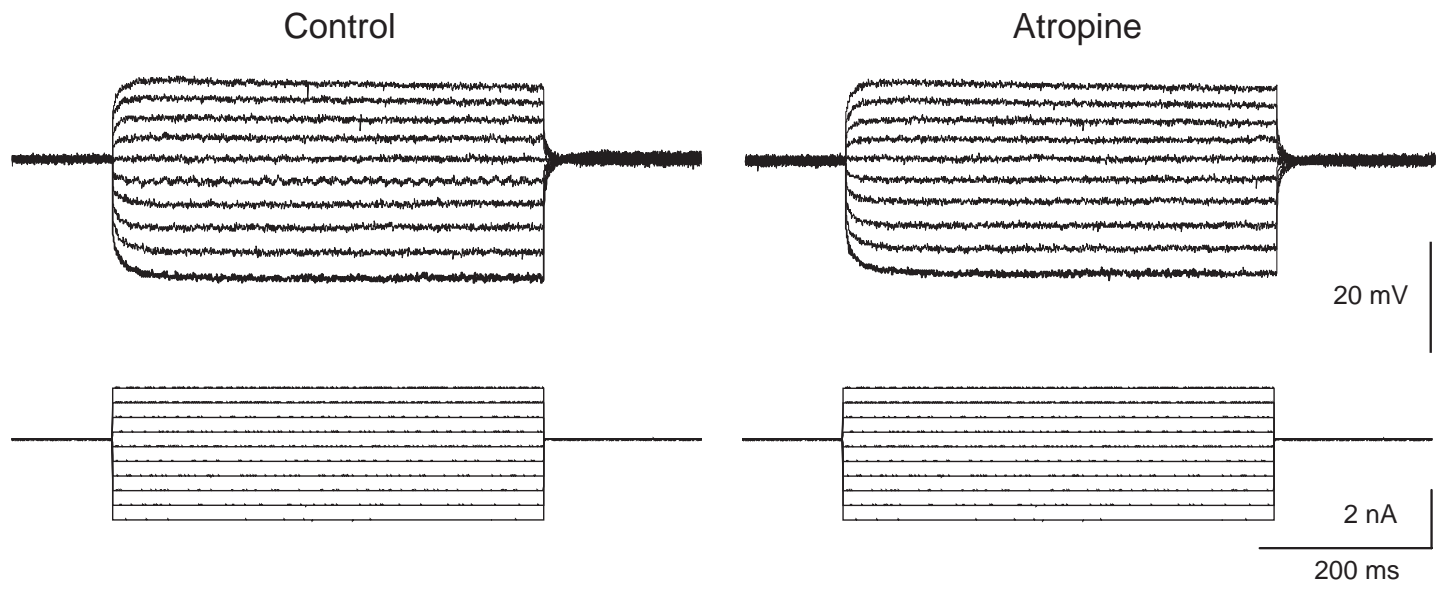

B2

B3
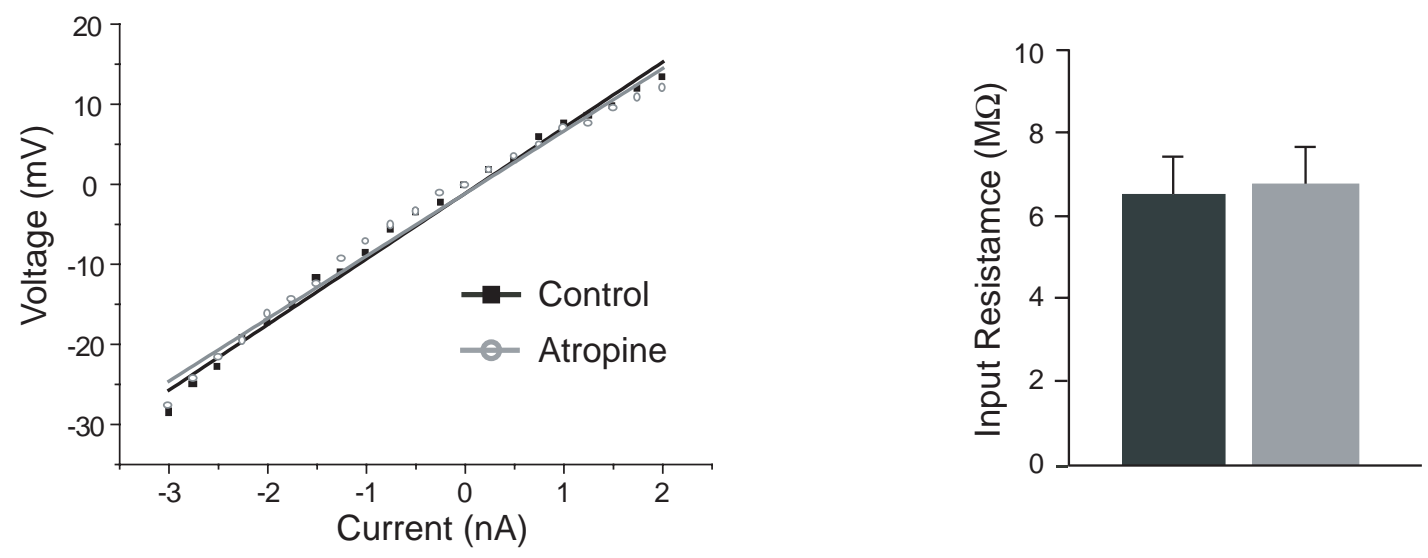

Control

Atropine 
Le Ray, Brocard \& Dubuc

Figure 4
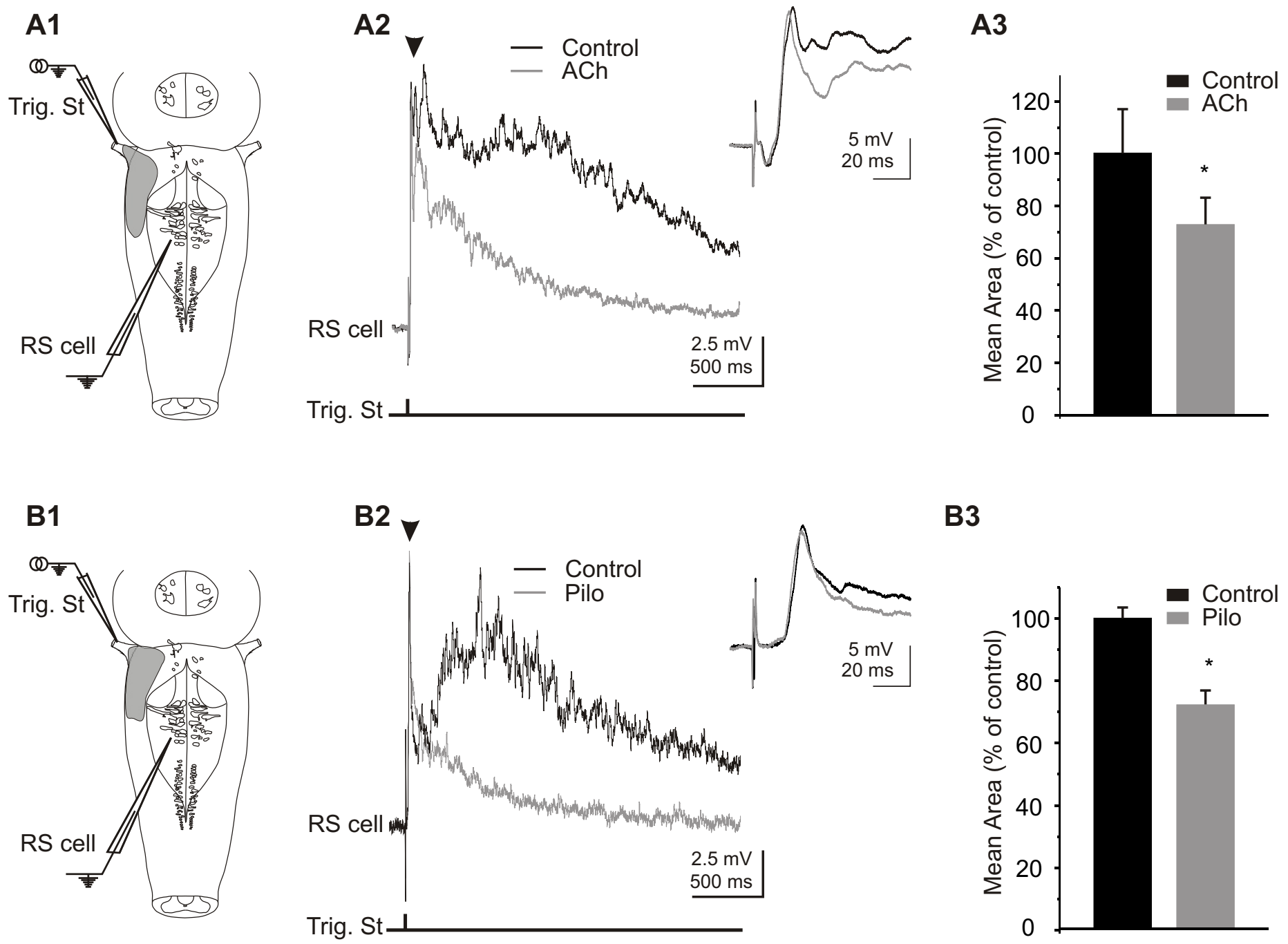

B3
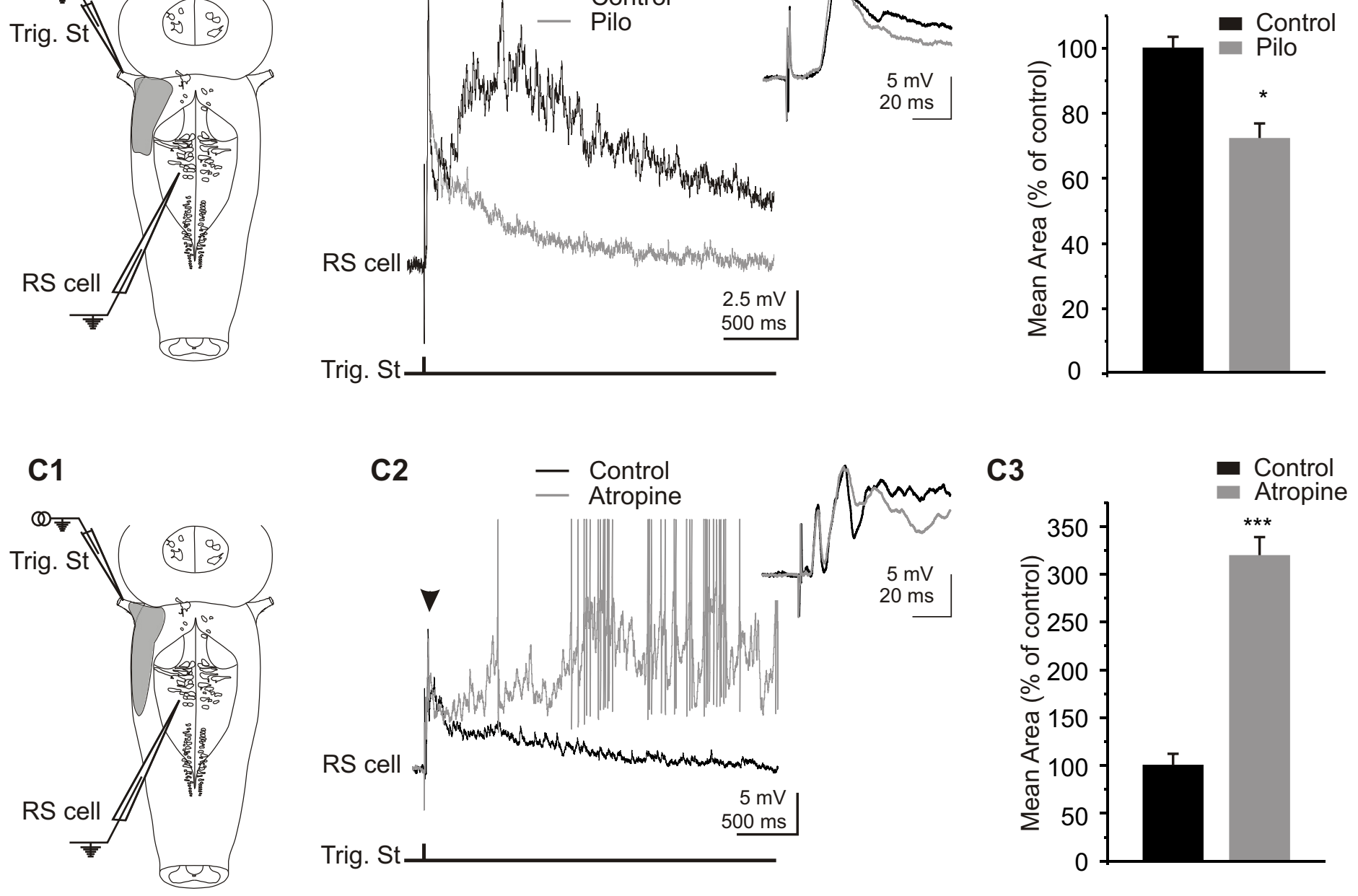


\section{Le Ray, Brocard \& Dubuc}

Figure 5
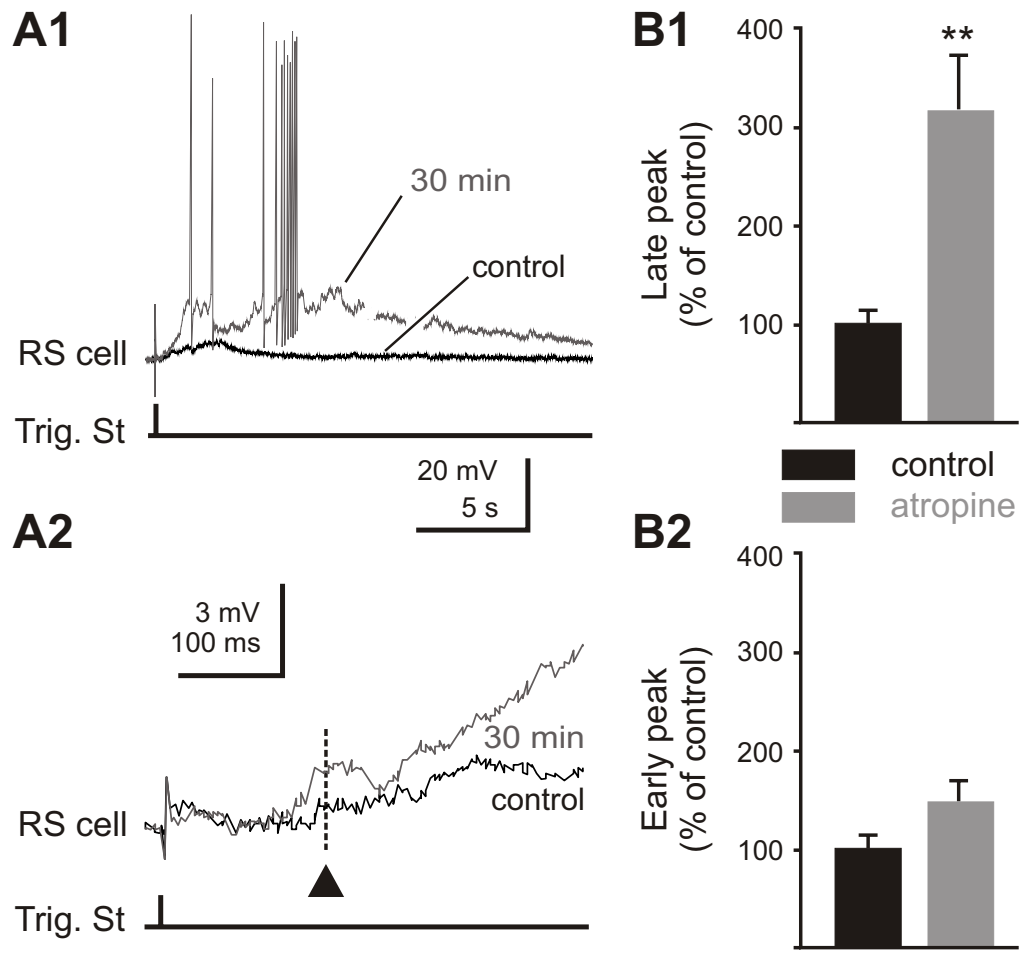
Le Ray, Brocard \& Dubuc

Figure 6

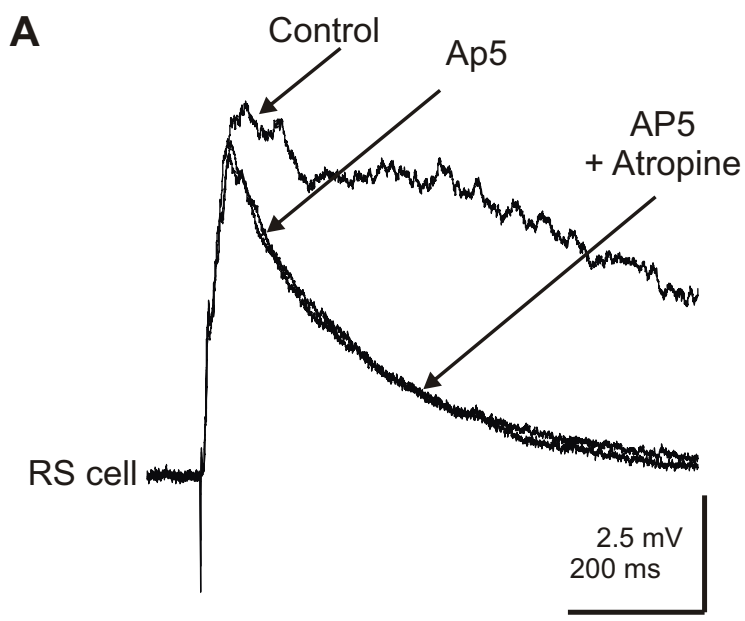

Trig. St $\perp$

B

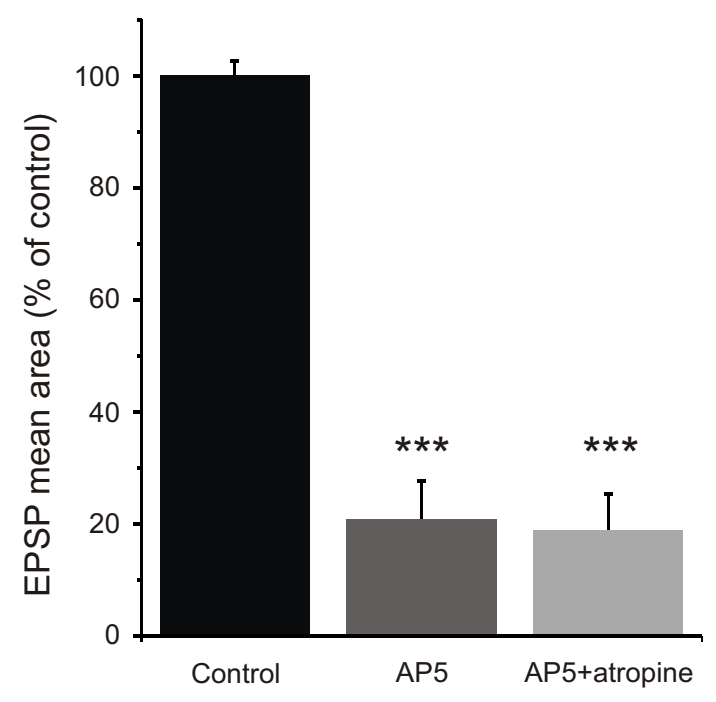




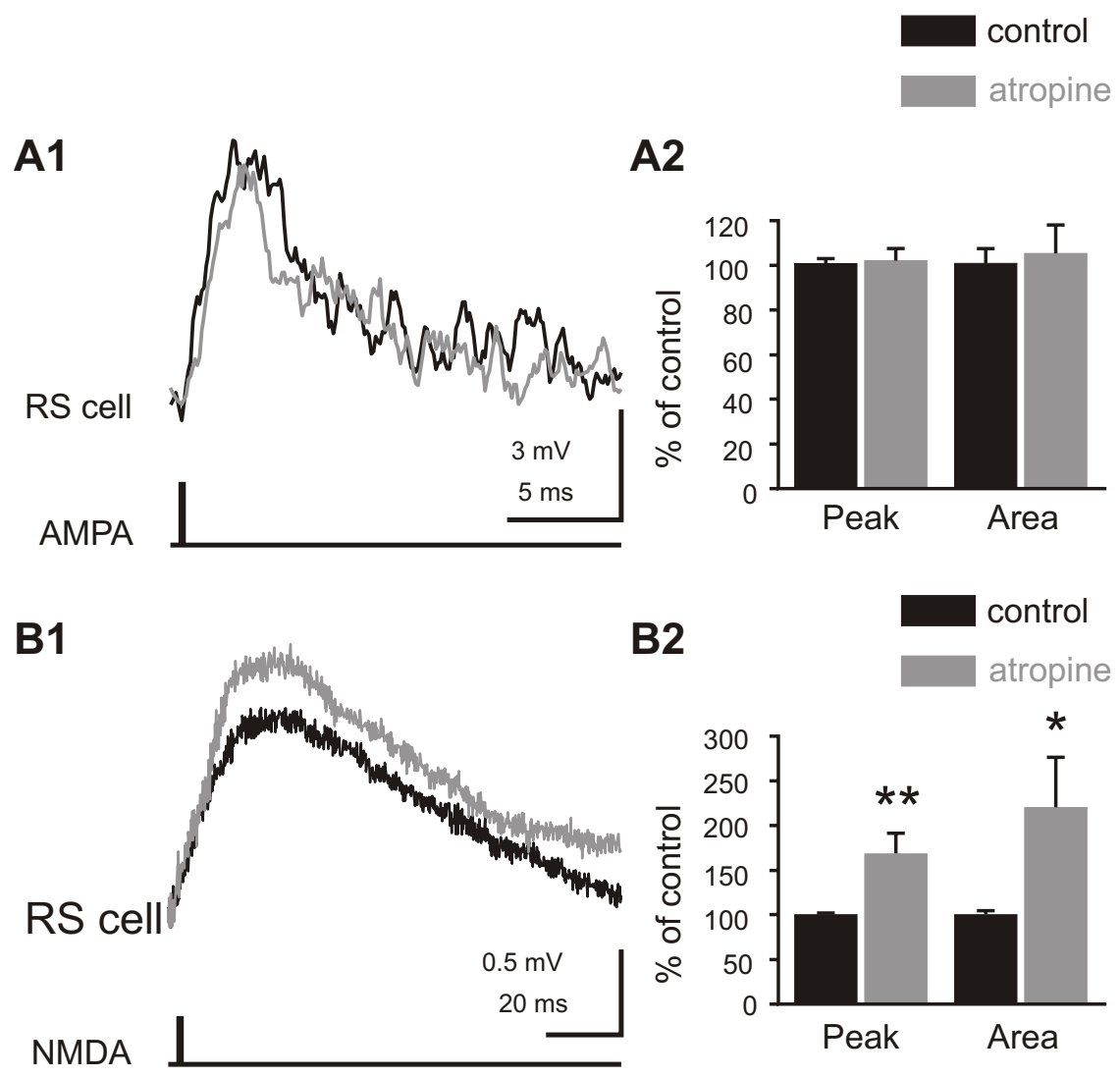



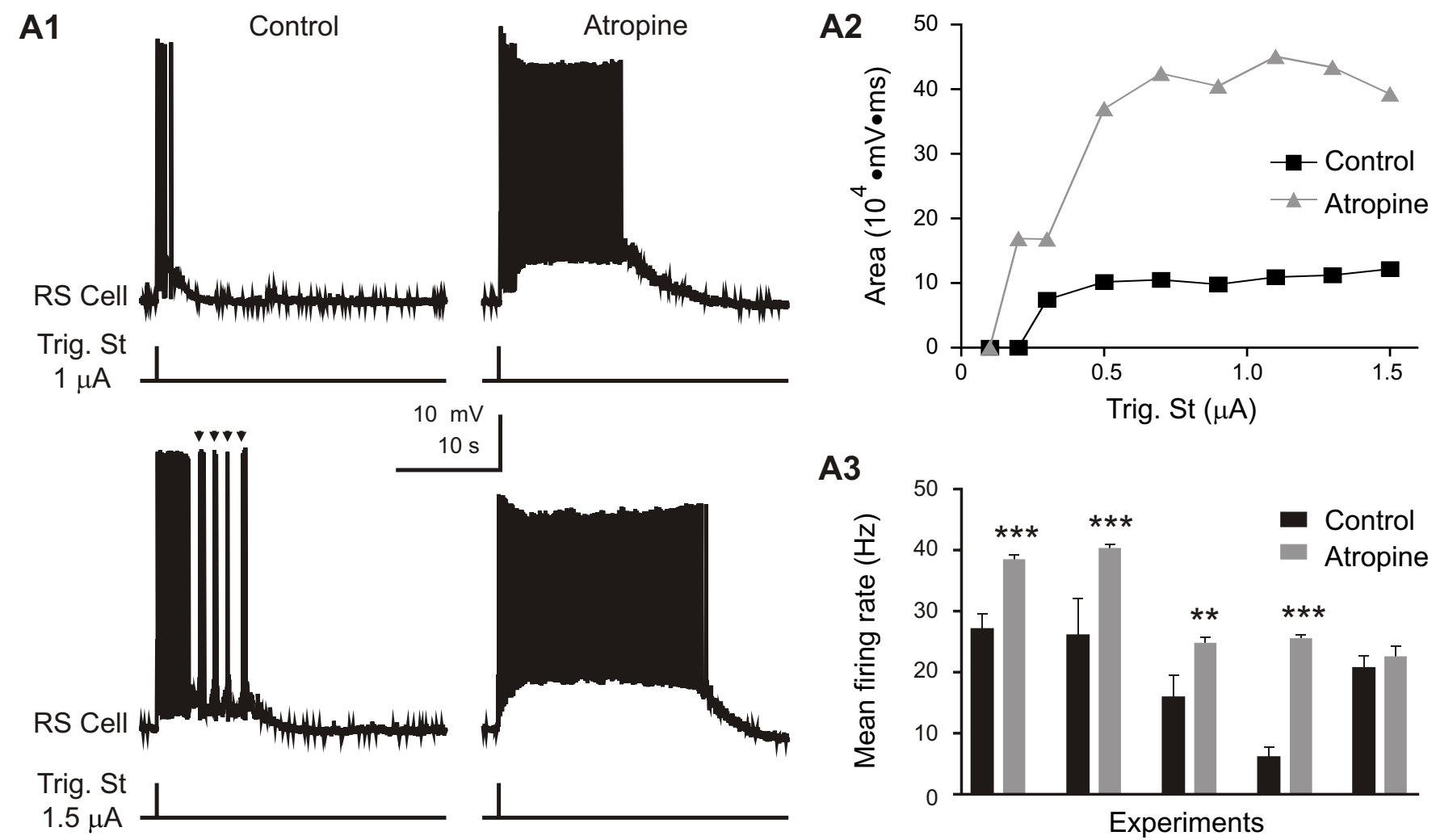

\section{B1}

Control

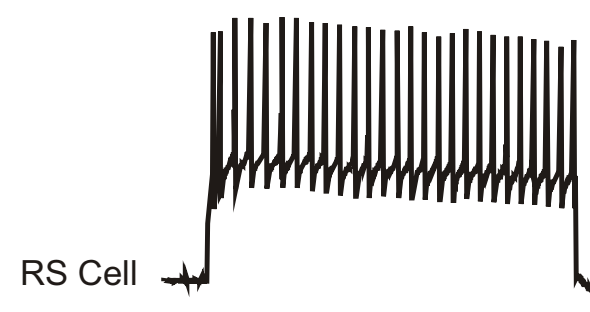

Atropine

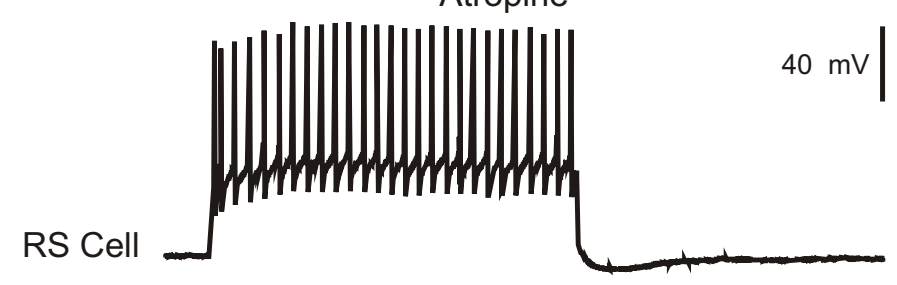

Current

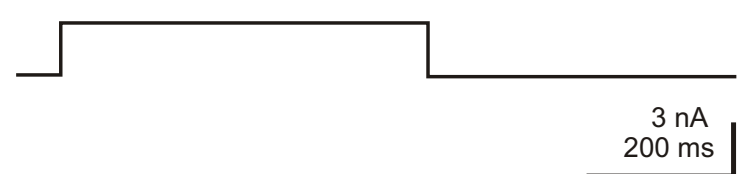

A3

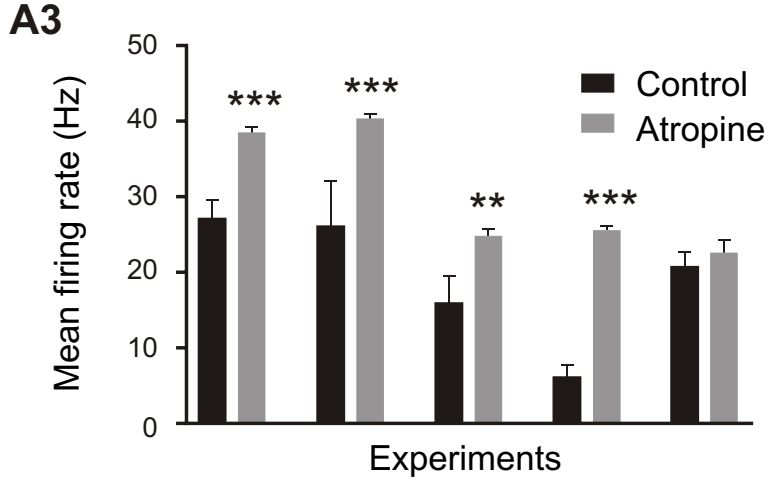

B2

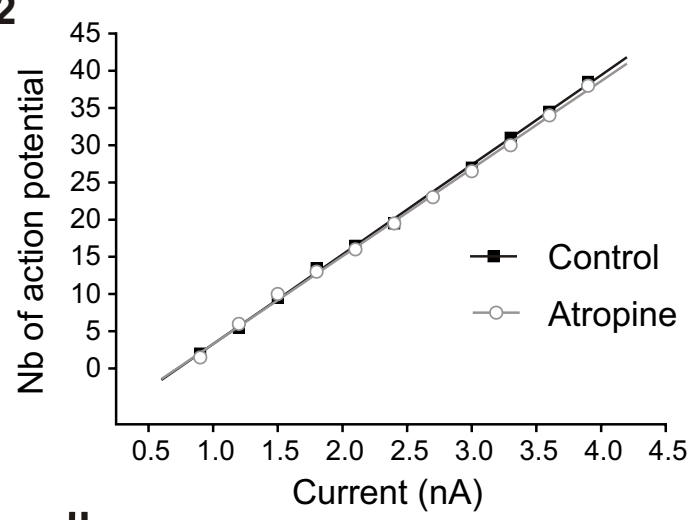

C

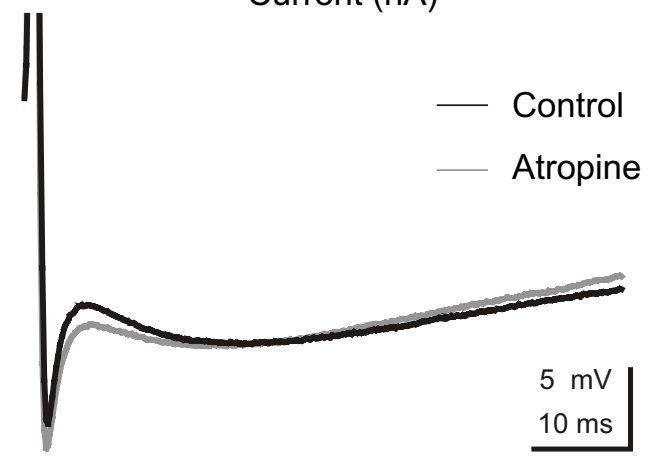




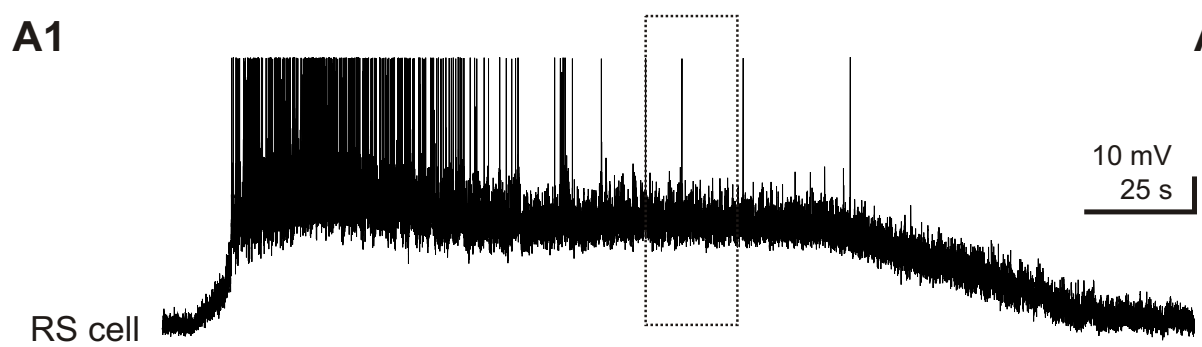

A2

NMDA

B1
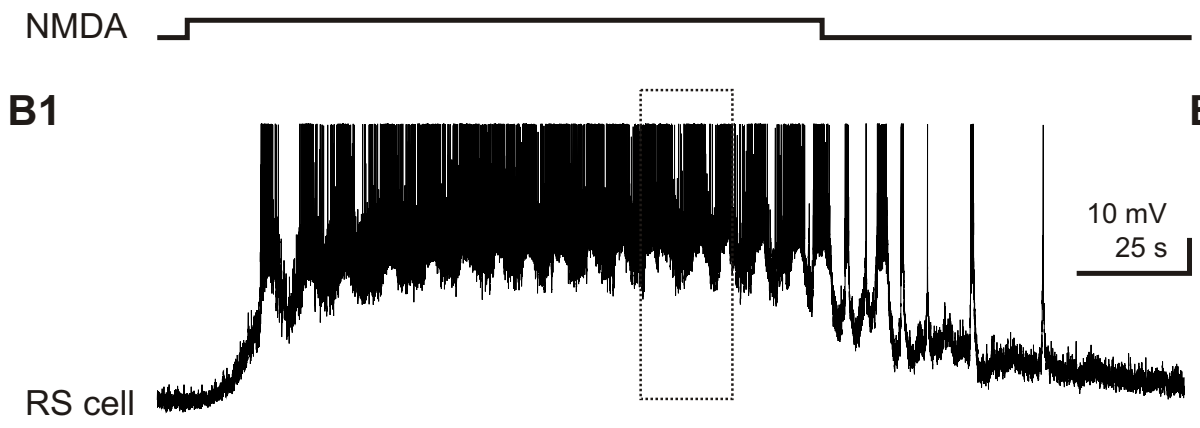

B2

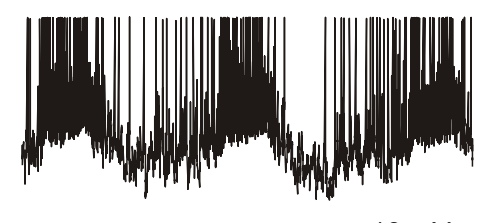

$10 \mathrm{mV}$

$5 \mathrm{~s}$

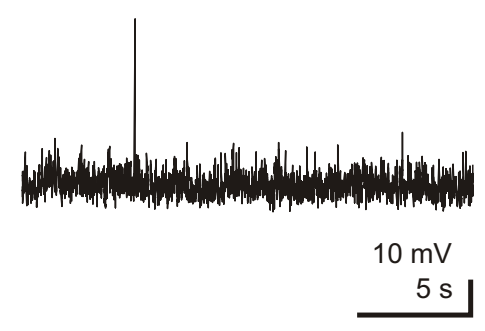

NMDA

C1

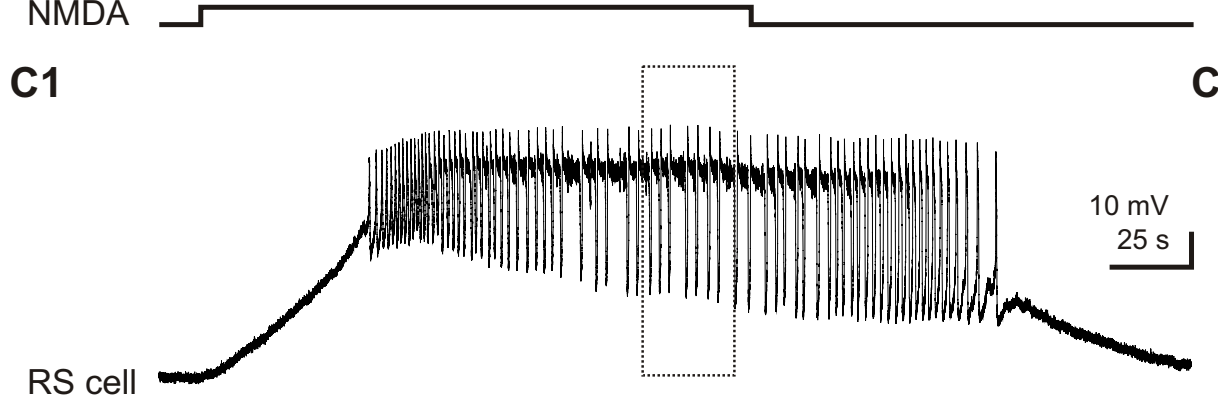

C2

NMDA

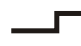

D1

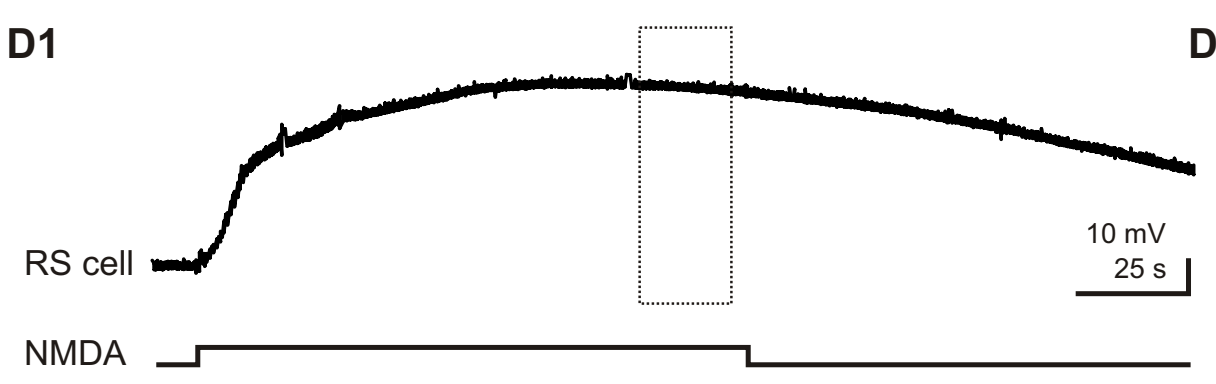

D2

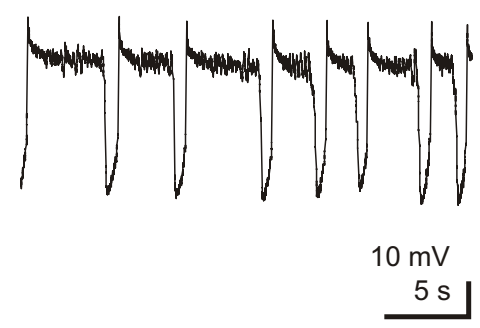

\section{2}

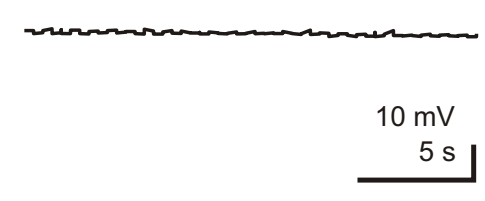


Le Ray, Brocard \& Dubuc

Figure 10

A1

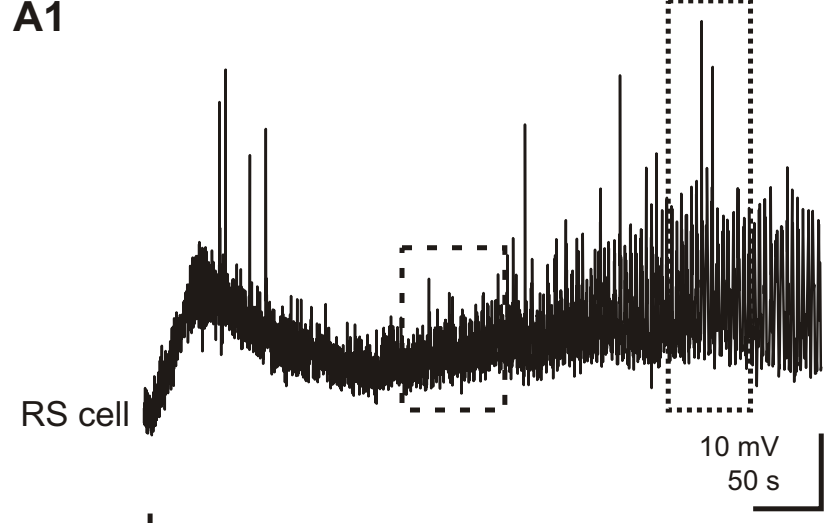

NMDA

B

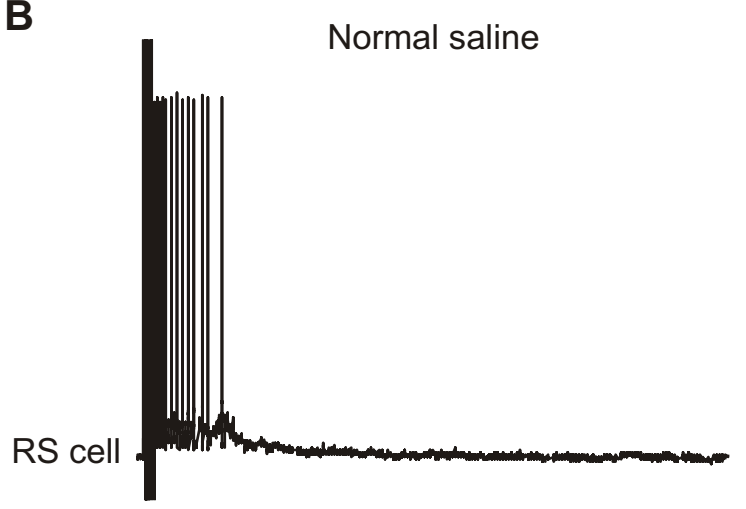

A2

RS cell
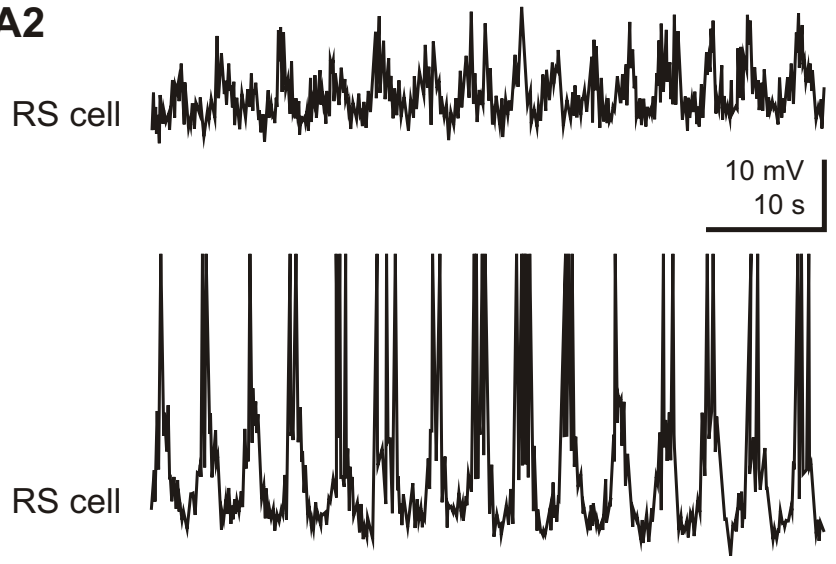

Atropine $10 \mu \mathrm{M}$

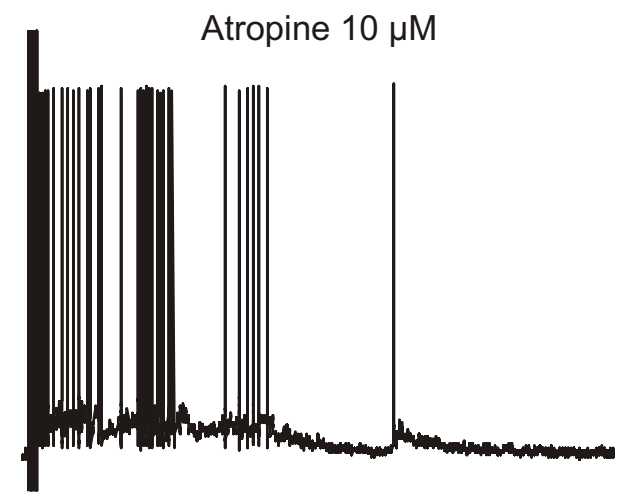

Atropine $10 \mu \mathrm{M}$ + FFA $200 \mu \mathrm{M}$

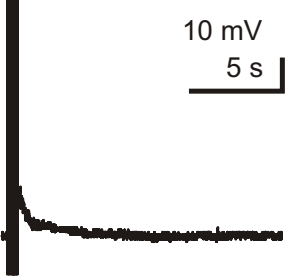

Trig. St 1

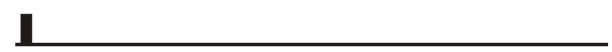

I 